\title{
Micro and nanoplastics in the environment: Research priorities for the near future
}

Marco Vighi ${ }^{1}$, Javier Bayo ${ }^{3}$, Francisca Fernández-Piñas ${ }^{4}$, Jesús Gago ${ }^{5}$, May Gómez ${ }^{6}$, Javier HernándezBorges $^{7,8}$, Alicia Herrera ${ }^{6}$, Junkal Landaburu ${ }^{1}$, Soledad Muniategui-Lorenzo ${ }^{9}$, Antonio-Román Muñoz ${ }^{10}$, Andreu Rico ${ }^{1}$, Cristina Romera-Castillo ${ }^{11}$, Lucía Viñas ${ }^{5}$, Roberto Rosal $^{2, *}$,

1 IMDEA-Water Institute, Avenida Punto Com 2, 28805 Alcalá de Henares, Madrid, Spain

2 Department of Chemical Engineering, University of Alcalá, E-28871 Alcalá de Henares, Madrid, Spain

3 Department of Chemical and Environmental Engineering, Technical University of Cartagena, Paseo Alfonso XIII 44, E-30203 Cartagena, Spain

4 Departamento de Biología, Facultad de Ciencias, Universidad Autónoma de Madrid, 28029 Madrid, Spain

5 Instituto Español de Oceanografía (IEO), Subida a Radio Faro, 50-52, 36390 Vigo, Spain

6 EOMAR: Marine Ecophysiology Group. IU-ECOAQUA. Universidad de Las Palmas de Gran Canaria, Campus de Tafira s/n, 35017 Las Palmas de Gran Canaria, Spain

7 Departamento de Química, Unidad Departamental de Química Analítica, Facultad de Ciencias, Universidad de La Laguna. Avda. Astrofísico Fco. Sánchez, s/n 38206 San Cristóbal de La Laguna, Spain

8 Instituto Universitario de Enfermedades Tropicales y Salud Pública de Canarias, Universidad de La Laguna. Avda. Astrofísico Fco. Sánchez, s/n 38206 San Cristóbal de La Laguna, Spain

9 Grupo Química Analítica Aplicada, Instituto Universitario de Medio Ambiente (IUMA), Centro de Investigaciones Científicas Avanzadas (CICA), Facultade de Ciencias. Universidade da Coruña, 15071 A Coruña, Spain*

10 Departamento de Biología Animal, Facultad de Ciencias, Universidad de Málaga, Málaga, Spain

11 Department of Marine Biology and Oceanography, Institut de Ciències del Mar-CSIC, 08003 Barcelona, Spain

\begin{abstract}
Plastic litter dispersed in the different environmental compartments represents one of the most concerning problems associated with human activities. Specifically, plastic particles in the micro and nano size scale are ubiquitous and represent a threat to human health and the environment. In the last few decades, a huge amount of research has been devoted to evaluating several aspects of micro/nanoplastic contamination: origin and emissions, presence in different compartments, environmental fate, effects on human health and the environment, transfer in the food web and the role of associated chemicals and microorganisms. Nevertheless, despite the bulk of information produced, several knowledge gaps still exist. The objective of this paper is to highlight the most important of these knowledge gaps and to provide suggestions for the main research needs required to describe and understand the most controversial points to better orient the research efforts for the near future. Some of the major issues that need further efforts to improve our knowledge on the exposure, effects and risk of micro/nano-plastics are: harmonization of sampling procedures; development of more accurate, less expensive and less time consuming analytical methods; assessment of degradation patterns and environmental fate of fragments; evaluating the capabilities for bioaccumulation and transfer to the food web; and evaluating the fate and the impact of chemicals and microorganisms associated with micro/nano-plastics. The major gaps in all sectors of our knowledge, from exposure to potentially harmful effects, refer to small size microplastics and, particularly, to the occurrence, fate, and effects of nanoplastics.
\end{abstract}

Keywords: Microplastics; nanoplastics; standardization; internalization; environmental risk; additives; microbial colonization.

*corresponding author: roberto.rosal@uah.es 


\section{Contents}

1. Introduction

2. Definitions

3. Research priorities

3.1. Environmental sources

3.2. Sampling procedures

3.3. Analytical methods

3.4. Additives and other non-intentionally added substances

3.5. Sorption of chemicals

3.6. Interaction with microorganisms

3.7. Degradation and fate of microplastics

3.8. Direct adverse effects of microplastics

3.9. Translocation and transfer to the food web

3.10. Nanoplastics

3. Conclusions and recommendations

Acknowledgements

References

\section{Abbreviations}

\begin{tabular}{|c|c|}
\hline ARB & Antibiotic resistant bacteria \\
\hline ARG & Antibiotic resistance genes \\
\hline AFM & Atomic force microscopy \\
\hline CEC & Contaminant of emerging concern \\
\hline DOC & Dissolved organic carbon \\
\hline DLS & Dynamic light scattering \\
\hline $\mathrm{DSC}$ & Differential scanning calorimetry \\
\hline GIT & Gastrointestinal tract \\
\hline HSI & Hyperspectral imaging \\
\hline LC50 & Lethal concentration for $50 \%$ of organisms \\
\hline MBR & Membrane bioreactor \\
\hline $\mathrm{M} / \mathrm{NPs}$ & Micro- and nanoplastics \\
\hline MP & Microplastic \\
\hline NGS & Next-generation sequencing \\
\hline NP & Nanoplastic \\
\hline NTA & Nanoparticle tracking analysis \\
\hline OCS & Operation clean sweep \\
\hline Py-GC-MS & Pyrolysis gas chromatography-mass spectrometry \\
\hline Py-GC-ToF & Pyrolysis gas chromatography time of flight mass spectrometry \\
\hline PA & Polyamide \\
\hline PCL & Polycaprolactone \\
\hline $\mathrm{PE}$ & Polyethylene \\
\hline PET & Polyethylene terephthalate \\
\hline PHB & Polyhydroxybutyrate \\
\hline PLA & Poly(lactic acid) \\
\hline PP & Polypropylene \\
\hline PS & Polystyrene \\
\hline PU & Polyurethane \\
\hline PVC & Poly(vinyl chloride) \\
\hline PCP & Personal care product \\
\hline TGA & Thermogravimetry \\
\hline WWTP & Wastewater treatment plant \\
\hline
\end{tabular}




\section{Introduction}

Although the first synthetic plastic polymer was discovered in the early 1900s (Andrady and Neal 2009), the presence of plastics in the world started to grow only in the 1950s eventually becoming ubiquitous and an integral part of modern life. Several reasons are explaining the enormous success of plastics. The extreme versatility of these materials, in terms of shapes, consistency, hardness and other properties, allow producing a practically endless variety of products. The possibility for manufacturing large series of items at low cost makes them the perfect material for producing disposable objects and all kinds of packaging. Plastics are almost chemically inert and may be easily sterilised, so they are excellent for containing food and for sanitary products. They are hardly altered and, therefore, the products made from them are long-lasting. However, this last property is also the main reason for the growing concern about plastics that raised worldwide: Plastics are highly persistent and, once introduced in the environment, it takes a very long time until they disappear.

Plastic manufacture represents about $6 \%$ of global oil consumption, and according to plastics usage projections, the plastics sector will account for $15 \%$ of the global emission of greenhouse gases by 2050 (WEF 2016). According to PlasticsEurope (2020), worldwide plastic production in 2019 amounted to 368 million tonnes. In Europe (EU plus UK, Norway and Switzerland), 29.1 million tonnes were collected as post-consumer waste through official schemes, equivalent to $47 \%$ of the amount of plastics produced in the same countries. Still, $25 \%$ of plastic post-consumer waste was sent to landfill and an undefined amount ended up in the environment (PlasticsEurope 2020). A large amount of these wastes ends up dispersed into the environment creating a worldwide pollution problem generally considered one of the major environmental issues associated to human activities (Baztan et al. 2017; GESAMP 2020; Koelmans et al. 2017a; UNEP 2016). Although most plastics come from land sources, the final receptor of plastic wastes are the oceans (Beaumont et al. 2019). Once there, they concentrate in particular areas due to the global cycle of currents, posing large risks for marine fauna (Kuhn et al. 2015; Lebreton et al. 2018; Thiel et al. 2018).

Once in the environment, plastic wastes suffer from several biotic and abiotic degradation processes. Abiotic mechanisms can be physical, which refers to erosion or fragmentation into smaller pieces, or chemical, due to the action of light and oxygen that lead to bond cleavage and the generation of molecules with new chemical moieties. The presence of light stabilizers or antioxidants, which are added to increase the service life of plastics, is another factor explaining the low environmental degradation rate of many plastics (Chamas et al. 2020). Biotic degradation generally follows abiotic fragmentation and takes place when microorganisms decompose break-down products under aerobic or anaerobic conditions to generate carbon dioxide, methane and biomass (Klein et al. 2018). The degradation of plastics also includes the leaching of additives included during compounding for a wide variety of purposes as well as non-intentionally added substances, which include impurities, catalysts, or polymerisation by-products. All of them become eventually leached out from plastic materials during environmental degradation processes. However, the complete degradation to carbon dioxide and water hardly occurs in the environment, making plastic debris and smaller particles prone to travel long distances and/or to accumulate in most environmental compartments.

Irrespectively of their origin, plastic particles are expected to pose a risk to the environment due to their inherent properties (i.e., molecular composition, additives, size and shape) or to environmental factors (Table 1). Risks associated with the inherent plastic properties can vary for the same polymer class due to differences in the manufacturing process. For example, a generic term for a class of plastic such as "polyethylene" (PE) includes many grades, differing in aspects like molecular weight, strength, crystallinity and even the detailed chemical structure, which leads to different monomer/oligomer release. Similarly, the additive composition can vary notably among polymers of the same class, and result in different chemical leaching characteristics. The physical impact of large plastics on biota is essentially independent of polymer characteristics or toxic substances, as is associated with a physical harm, mainly related to their size and shape. Small debris may cause the blockage of the intestines of small animals and, for sufficiently small particles, there is the possibility of transfer through the food web and even translocate to tissues, thereby 
originating true toxic effects. The environmental factors are associated to the characteristics of the external medium, like the concentration of other pollutants, temperature, salinity or presence of potentially colonizing microorganisms. Similar microplastics (MPs) can behave differently in the environment depending on external variables providing some kind of "en route" signature (Leslie et al. 2017), which determines its capacity to disseminate microbial pathogens and transfer pollutants to living organisms. In addition, plastic debris could affect some aspects of the functioning of the ecosystem. For example, it has been hypothesized that they can contribute to decrease marine primary productivity and influence the carbon and nutrient cycles (Troost et al. 2018); however, further research is needed to provide a solid demonstration.

Table 1. Potential risks associated to plastic particles according to their properties and environmental factors.

\begin{tabular}{|l|l|}
\hline \multirow{4}{*}{$\begin{array}{l}\text { Plastics } \\
\text { properties }\end{array}$} & i) Transfer of additives used in the production of plastics-Section 3.4 \\
\hline & ii) Release of unreacted monomers/oligomers-Section 3.4 \\
\hline & iii) Physical impact on biota (higher size particles)-Section 3.8 \\
\hline & iv) Translocation and transfer to the food web-Section 3.9 \\
\hline $\begin{array}{l}\text { Environmental } \\
\text { factors }\end{array}$ & v) Transfer of adsorbed environmental pollutants-Section 3.5 \\
\cline { 2 - 2 } & vi) Transport of non-indigenous species in the environment-Section 3.6 \\
\hline
\end{tabular}

In the last few decades, huge research activity has been developed on the study of MPs and an enormous number of research papers and reviews have been published to quantify their presence in environmental compartments (Andrady 2011; Auta et al. 2017; Eerkes-Medrano et al. 2015; Li et al. 2018; Schell et al. 2020b); to evaluate their effects and risks for aquatic and terrestrial organisms (Burns and Boxall 2018; Chae and An 2018; de Sá et al. 2018); to assess their bioaccumulation and the effects of associated chemicals (Crawford and Quinn 2017; Verma et al. 2016; Wright et al. 2013); and to model their environmental behaviour (Everaert et al. 2018; Koelmans et al. 2016). Several international organisations and working groups have produced important technical reports and opinions (GESAMP 2015; GESAMP 2016; SAM 2019; SAPEA 2019). A considerable number of international research projects have been funded in the last few years (notably, under JPI Oceans) and specific calls on this topic have been recently launched (H2020 under Food security and Environment Programmes). Despite this bulk of information, several knowledge gaps still exist that, in many cases, affect the relevance and the reliability of existing information. For example, the lack of harmonisation and standardisation of sampling and analytical methods makes it difficult to compare different studies. Therefore, even fundamental information like actual exposure in environmental compartments becomes difficult to judge.

Regulatory restrictions on MPs started in 2015 with the Microbead-Free Waters Act (USA) prohibiting the manufacturing and distribution of cosmetics containing plastic microbeads. A broader regulation came from a proposal from the European Chemicals Agency (ECHA) upon request of the European Commission to ban MPs intentionally added to a variety of goods including cosmetics, cleaning agents, paints, and some industrial products. ECHA's restriction is currently under study in the European Parliament and the Council. In the meantime, some EU and non-EU countries, starting by the Netherlands, introduced different limitations in MP beads in cosmetic products. In 2019, the European Parliament voted the Directive 2019/904 on the reduction of the impact of certain plastic products on the environment, meaning single-use plastics and fishing gear containing plastic, which bans single-use plastic products by 2021 , extends producer's responsibility schemes based on polluter-pays principle for items without available sustainable alternatives, and set the responsibility of Member States with marine waters for the collection of waste fishing gear containing plastic. As in the case of primary MPs, several countries already adopted or announced actions to limit the use of plastic starting by plastic bags and single use items. Additional provisions have been included in the amended Waste Framework Directive while others are being considered by the EU Commission, US EPA and other Governments and agencies with different rate, extension, and credibility. 
The objective of this paper is not to provide an additional review on the presence and risks of microplastics and nanoplastics (M/NPs) in the environment, but to highlight and describe the major knowledge gaps and controversial points that researchers should deal with in the near future. A clear picture of the main research needs could be the fundamental basis for the coordination of future research efforts and for the development of specific project calls, at national and international level. This will allow developing proposals to cover these gaps and to improve our knowledge on the exposure, effect and risks of M/NPs, increasing our capability to develop risk mitigation measures to counteract one of the most important environmental problems in the start of the third millennium.

\section{Definitions}

Before presenting the main knowledge gaps and research priorities, a brief note on conventions and arbitrary definitions is needed. MPs are defined as fragments having $<5 \mathrm{~mm}$ along its largest dimension, (GESAMP 2019). Recently, Frias and Nash defined MPs as "synthetic solid particle or polymeric matrix, with regular or irregular shape and with size ranging from $1 \mu \mathrm{m}$ to $5 \mathrm{~mm}$, of either of primary or secondary manufacturing origin, which are insoluble in water" (Frias and Nash 2019). The definition should be broad enough to include natural polymers processed in such a way that they constitute anthropogenic litter, if spread into the environment (Hartmann et al. 2019). This definition, despite arbitrary and imprecise regarding its nomenclature (i.e., MP should include the $\mu \mathrm{m}$ range, and there is no reason to span to the $\mathrm{mm}$ range) has been adopted for the sake of harmonization after certain controversy (GESAMP 2019).

MPs are heterogeneous, exhibiting a range of shapes or morphologies from spherical beads to angular fragments and long fibres (Fig. 1). According to their origin, MPs are either primary or secondary. Primary MPs have been specifically manufactured with their size and include virgin plastic pellets used as raw materials for the fabrication of different products (Browne et al. 2011; Fendall and Sewell 2009; GESAMP 2019). According to GESAMP, secondary MPs "result from wear and tear or fragmentation of larger objects" (GESAMP 2019). The shape of plastic fragments is relevant because it determines drag, the viscous force exerted by a flowing fluid on any submerged particle that governs its terminal settling velocity and, therefore, the time a particle is being transported by water or air. Besides, and concerning the smaller sizes, particle shape influences suspension stability (Kim et al. 2015).

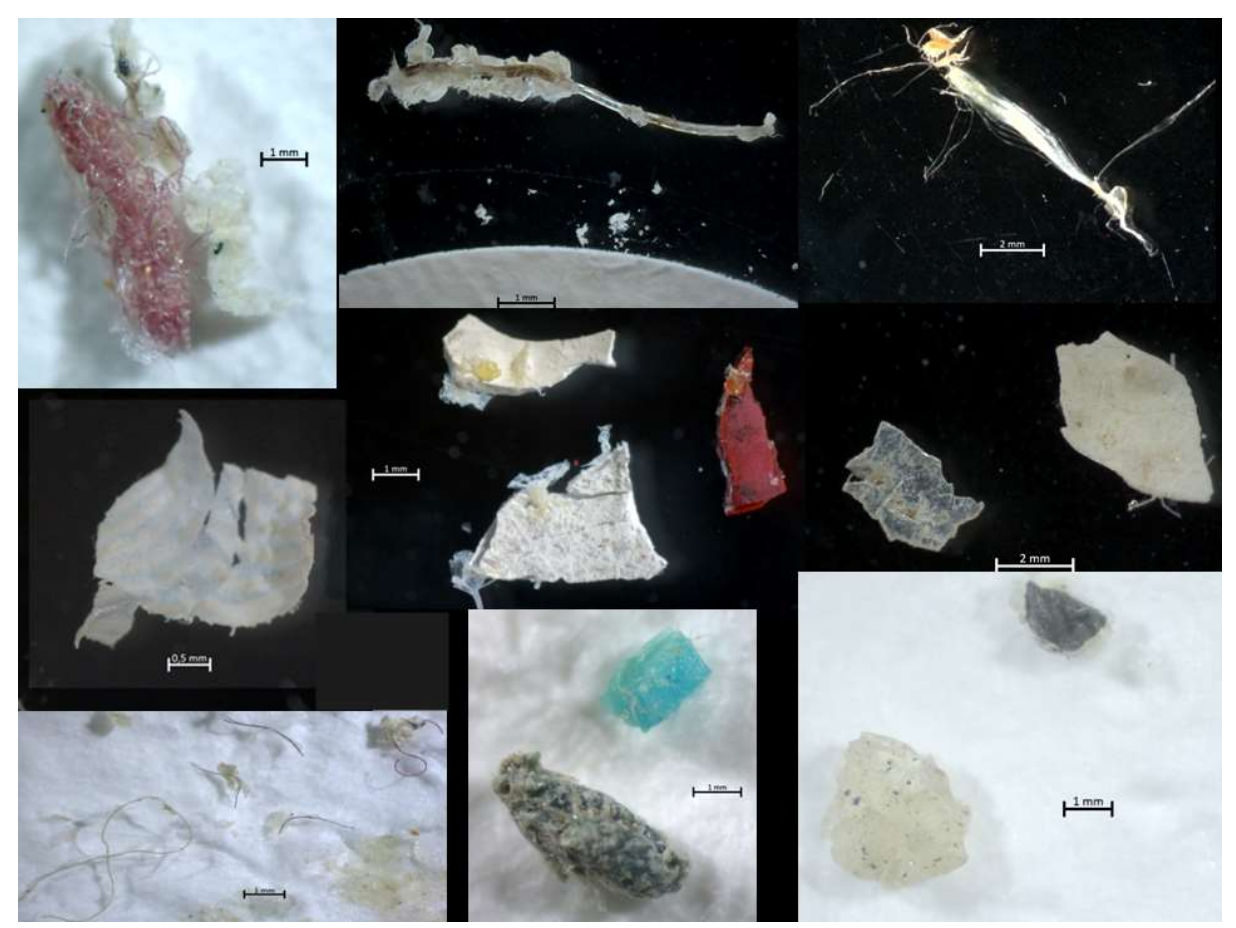

Figure 1. Photographs of different types of MPs collected in seawater in Ría de Vigo, NW Spain. Source: Instituto Español de Oceanografía. 
Concerning nanoplastics (NPs), the scientific literature used at least two different definitions: (i) Nano-sized plastic particles < $1000 \mathrm{~nm}$ (Andrady 2011; Cole et al. 2011); and ii) Nanoplastics $<100 \mathrm{~nm}$ (in at least one of its dimensions) as defined for engineered nanoparticles (Bergami et al. 2016; Koelmans 2015). Lately, the first option, that considers NPs as unintentionally produced plastic particles with colloidal behaviour, and size range from 1 to $1000 \mathrm{~nm}$ has gained popularity (Gigault et al. 2018). GESAMP also accepted this boundary, which must be understood as referred to the largest dimension by analogy with MPs (GESAMP 2019). The plain use of the $1000 \mathrm{~nm}$ boundary without the limitation to unintentionally produced or secondary particles is less controversial (Hartmann et al. 2019).

Although detected in essentially all ecosystems (Gago et al. 2018), the current debate on M/NPs tends to exclude fibres (Frias and Nash 2019; Henry et al. 2019). Polymeric fibres are produced by textile wearing, particularly during laundry (Napper and Thompson 2016). Before reaching conclusions on the impact assessment of fibres, two main methodological gaps need to be addressed. First, the lack of a proper definition of "size" in the case of fibres. Second, the definition of fibres of concern in the context of plastic pollution. Both aspects require clarification and standardization.

In the case of fibres, their largest dimension is particularly meaningless to establish cut-off among categories because large fibrous materials may pass through filters with smaller opening size, thereby complicating quantification. The behaviour of a fibre inside a fluid medium depends on its Stokes' or aerodynamic diameter. Accordingly, the relevant or characteristic dimension of a fibre is its equivalent diameter, which is generally a linear function of their physical diameter and depends less on fibre length. Besides, fibres are flexible. A clear definition of size cut-offs for fibres, and in general for particles of low sphericity is lacking.

Besides, there is an issue concerning nomenclature. The term "microfibre" is common in many environmental studies as a synonym of "microplastic fibre" or synthetic fibre within the MP size range, but the denomination is controversial. There is a technical definition of microfibres to refer to a mass per unit length of thread, which can be conflicting. Some authors recommend avoiding the term "microfibre" and others suggest including a minimum length to diameter ratio in the definition (Liu et al. 2019b; SalvadorCesa et al. 2017). The term "nanofibre" is also debated: the industry often considers "nanofibres" objects with diameters as large as $500 \mathrm{~nm}$ or $1000 \mathrm{~nm}$.

An additional issue concerning fibre composition is a need to include as anthropogenic debris not only those made of synthetic polymers, but also regenerated cellulose textiles (like rayon and lyocell). Both are included under the heading "man-made fibres" in ISO/TR 11827 Textiles - Composition testing Identification of fibres. Besides, natural fibres that show evidence of industrial processing should be considered as a category of anthropogenic litter because they incorporate additives like bleaching agents, softening, or stiffening additives, synthetic dyes, light stabilizers, and flame retardants among others (Darbra et al. 2012). Clearly, fibres made of synthetic polymers, regenerated cellulose, or processed natural materials are generally sampled together. Moreover, the textile industry is moving towards the production of a wide range of hybrid natural/synthetic fabrics.

\section{Research priorities}

\subsection{Environmental sources}

\section{State of the art}

Intentionally manufactured MPs, or primary MPs, are used with different purposes in many products. These include scrubbing phase in personal care products (PCPs), encapsulating agent for fragrances in detergents and softeners, or with several technical functions in fertilizers and plant protection products for agriculture, paints, coatings, inks, medical products and devices, or food supplements. Most of these primary MPs are extremely persistent materials whose exposure could result in adverse effects nowadays or in the future due to continued use and the difficulty of being removed once in the environment. Therefore, there is a need in 
the industry for a transition to more suitable alternatives like natural products in PCPs or biodegradable polymers for other technical functions. In the United States, the Microbead Free Waters Act of 2015 banned the manufacturing and distribution of cosmetics containing rinse-off plastic microbeads. In Europe, a wider restriction has been proposed by the European Chemicals Agency (ECHA 2019). The restriction affects a range of products in different sectors, including domestic and industrial uses. Several EU Member States have already introduced partial bans for MPs in specific products. Some exemptions are considered like MPs for use at industrial sites and in medical products for human or veterinary use, among others.

Secondary MPs have several different origins. Wastewater treatment plants (WWTP) have been identified as one of the main point sources of MPs in freshwater (Carr et al. 2016). Most studies indicated that primary and secondary wastewater treatments remove most MPs. Murphy et al. reported $98 \%$ of MPs removal from a conventional secondary WWTP plant located in Scotland (Murphy et al. 2016). Talvitie et al. observed 99 $\%$ MP removal from a secondary WWTP, the primary treatment already removing $97.4 \%-98.4 \%$ (Talvitie et al. 2017b). The same group evaluated four different wastewater treatment technologies (disc filters, rapid sand filters, dissolved air floatation and membrane bioreactor). They concluded that membrane bioreactor (MBR) was the most efficient technology with $99.9 \%$ removal capacity (Talvitie et al. 2017a). However, despite the high removal ability of current wastewater treatment technologies, and due to the high volume of treated wastewater continuously emitted to the environment, there is still a considerable emission of MPs from WWTPs to rivers. Edo et al. (2020) reported a release of 300 million MP particles $(>25 \mu \mathrm{m})$ per day from a Spanish WWTP to the Henares River representing an approximate load of MPs of 350 particles $/ \mathrm{m}^{3}$ (Edo et al. 2020). One major contribution to MPs reaching WWTP is the wearing of synthetic clothes in domestic washing machines, notably those made of polyester and acrylic fibres (Napper and Thompson 2016). Additionally, industrially processed natural fibres, which contain potentially harmful additives, reach the environment in the same way (Edo et al. 2020). Fragments and other secondary plastic debris are also usual in the effluents of WWTP, which constitute a vehicle for them to reach freshwater and seawater environments (Bayo et al. 2020).

Stormwater runoff from urban and agricultural soils has been shown to represent an important source of MP pollution. Commercial and industrial areas are major contributors while synthetic rubber particles attributed to car tyre wear mostly appear in sediments due to road runoff (Liu et al. 2019a; Ziajahromi et al. 2020). Besides, plastic debris from materials used in the construction of wetlands, rests from agricultural plastics and many other secondary MPs reach natural environments driven by wind (Zhang et al. 2019b). A precise estimation of MPs emissions due to water runoff and atmospheric transport is difficult due the limited data available.

The atmosphere is the less studied environmental compartment concerning the occurrence and transport of MPs. The occurrence of airborne MPs has been documented in studies at ground or near-to-ground level (Brahney et al. 2020; Klein and Fischer 2019). Recently, and for the first time, direct evidence of the presence of MPs at high altitudes has been provided that demonstrate their presence even beyond the planetary boundary layer (González-Pleiter et al. 2021). The available data are difficult to interpret due to the rapid atmospheric mixing and the occurrence of random deposition events, but generally suggest that the source of most airborne MPs is urban due to the higher concentrations detected near populated areas (Wright et al. 2020). However, the mobility of airborne MPs is high, and they can be transported to areas far from any source of pollution (Bergmann et al. 2019; Bullard et al. 2021). The literature reports concentrations in the order of a few MPs per cubic meter and deposition rates reaching values up to the order of hundreds of MPs per square meter and day (Abbasi et al. 2019; Dris et al. 2016).

The use of plastic packaging in the food sector clearly proved to be a vehicle for MPs release to packaged food (Fadare et al. 2020; Kedzierski et al. 2020). Trays made from extruded polystyrene have been deemed responsible for food transfer of MPs in levels ranging from 4.0 to $18.7 \mathrm{MP} / \mathrm{kg}$ of packaged food (Kedzierski et al. 2020). The occurrence of MPs in drinking water, both tap and bottled, has also been studied with results showing concentrations in the order of tens of MPs per litre (Schymanski et al. 2018; Shruti et al. 2020). Food plastic packaging enhances storage, transport, protection, and preservation, but contributes to 
human exposure to MPs in products intended for human consumption. The presence of MPs in food is a topic widely covered in the literature with estimations of annual MP intake in order of tens of thousands of particles (Cox et al. 2019). Teabags packaging were shown to release billions $\left(10^{9}\right)$ of M/NP particles (polyacrylate, and polyethylene terephthalate, PET) into a single cup of beverage (Hernandez et al. 2019). MPs in a wide array of seafood products have been detected due to the pollution of seas (Sun et al. 2019).

\section{Knowledge gaps and research needs}

In view of the increasing regulatory restrictions affecting intentionally manufactured MPs, it is foreseen that they will represent a minor cause for concern in the future. Additionally, it has been observed that $<10 \%$ of the MPs found in the effluent of WWTPs are pellets, which can be classified as primary MPs) (Dyachenko et al. 2017). Therefore, it can be concluded that secondary MPs represent a bigger threat than intentionally manufactured MPs. This includes a better management of plastic litter, which, in the form of larger debris (mesoplastics, $5-25 \mathrm{~mm}$ or macroplastics, $>25 \mathrm{~mm}$ ) is an important source of M/NPs due to fragmentation, and the limitation of unnecessary plastic items like plastic packaging materials. Most of the original research efforts have been conducted on the marine environment. More studies are needed about MPs in freshwaters, which proved to be receiving bodies comparable to the marine environment ( $\mathrm{Li}$ et al. 2018). An important limitation for assessing the fate of M/NPs is the limited data available for assessing the sources and the origin (e.g., primary or secondary MNPs) and the mass balance in the different environmental compartments (water, air, soil) of the smaller sizes of MPs and of NPs (Schell et al. 2020b).

A deeper insight into WWTP processes is required to avoid MPs emissions. The understanding of physical, chemical and biological mechanisms affecting MPs in WWTP is a related need (Bayo et al. 2020). Even if removal rates are high in conventional WWTP and most MPs are recovered with sludge, they find a way to go back to the environment via sludge use in agriculture as fertilizer. Several studies revealed a concentration of MPs in sewage sludge ranging from a few to several hundred particles per gram of dry sludge (Edo et al. 2020; Magni et al. 2019). Accordingly, synthetic polymers mainly consisting of fibres can be detected in agricultural soils even years after sludge application (Zubris and Richards 2005). Therefore, ways of managing WWTP sludge that ensures its safety and avoids the spreading of MPs into the environment need to be urgently developed ensuring a safe use by source separation, composting or risk assessment.

The generation of secondary M/NPs from food contact materials, and human exposure to them is a major cause for concern nowadays, even in the absence of evidence about their risk for human health. Quantitative data are needed on the presence of MPs in food from plastic containers and the contribution of food packaging to the global emissions of M/NPs. There are very limited data on the smaller sizes of MPs and on NPs, which are the size ranges of higher concern.

Overall, limited data exist on the occurrence and transport of MPs in important environmental compartments. There are only a few studies addressing the atmospheric deposition rates of MPs and no data truly reporting their occurrence in the atmosphere. Data from soil and sediments are also scarce and fragmentary and little is known about the role played by sea bottoms as an ultimate sink. The relevance of the different transport pathways for the environmental distribution of M/NPs is challenged by the limited amount of data. The data required for modelling are globally insufficient and, in some regions, relies on extrapolations made with too many uncertainties.

\subsection{Sampling procedures}

\section{State of the art}

Sampling campaigns in surface water (particularly in the sea) are usually performed using manta trawl nets with a mesh size usually in the 200-500 $\mu \mathrm{m}$ range (Fig. 2 and Table 2). Data are usually reported as MPs $/ \mathrm{km}^{2}$. The use of flowmeters is highly recommended to report data in MP/m $/ \mathrm{m}^{3}$. Sampling should be 
carried out under optimal sea conditions, with a Beaufort scale between 0 and 2. Otherwise, it is necessary to do the calculations of wind correction factor as proposed by Kukulka et al. (2012) who showed that under strong wind conditions neuston nets tend to collect fewer plastic particles due to vertical wind-induced mixing (Kukulka et al. 2012). In some cases, water is pumped into the nets (Fig. 3).
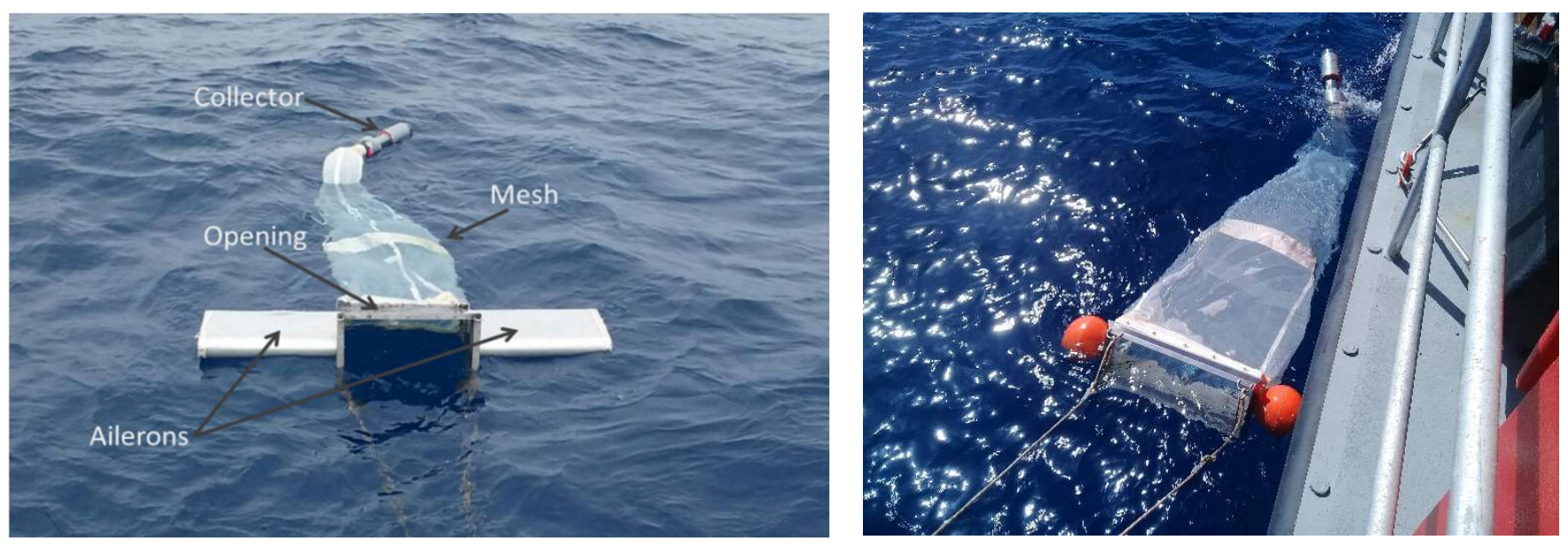

Figure 2. Manta net picture and its parts (left): stainless steel structure with a front opening of $60 \mathrm{x} 40 \mathrm{~cm}$ and rear opening of $60 \times 25 \mathrm{~cm}$. On the sides, two stainless steel ailerons. Some modifications are used such as the use of buoys (right). Source: EOMAR-Universidad de Las Palmas de Gran Canaria.

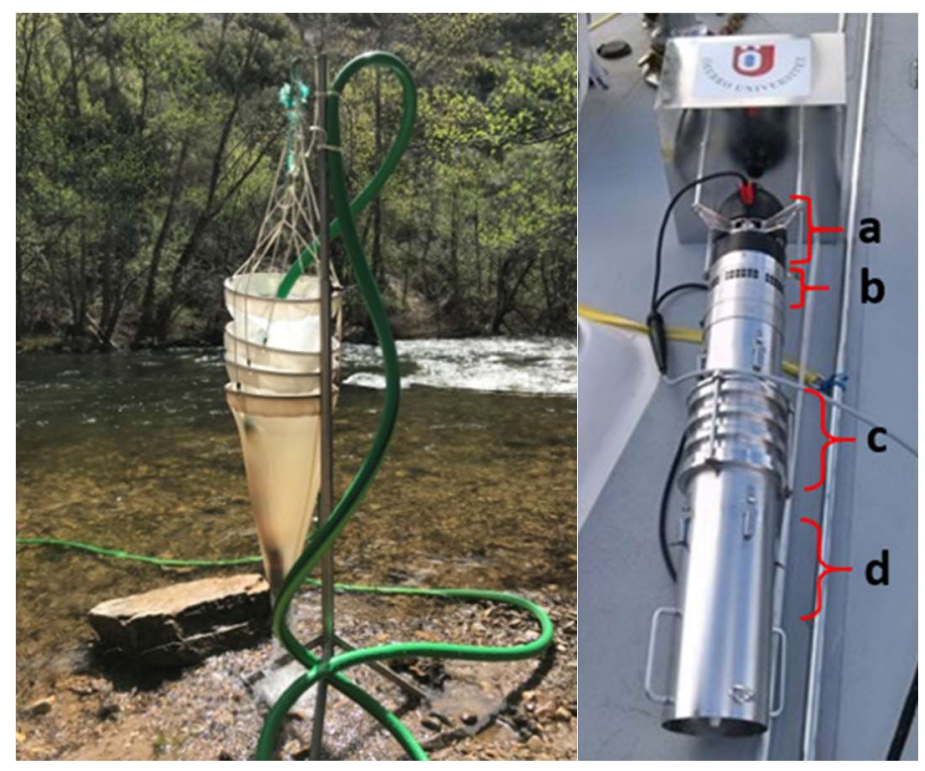

Figure 3. Example of sampling in a river with a battery of nets with different mesh size fed by a pump with known water flow. Source: IMDEA Water (Madrid Institute for Advanced Studies on Water, Spain, left). In situ pump built by KC Denmark (Silkeborg, Denmark) and EU CleanSea project; a: Faulhaber Swiss motor system, 3863H0224CR - 24V, GB $150 \mathrm{~nm}$ with a planetary gearing 44/1 - 4,8:1 $16 \mathrm{~nm}$; b: Water inlet with rotating blades to pull in the surrounding water; c: stack of filters with inserted $500 \mu \mathrm{m}, 300 \mu \mathrm{m}$ and $50 \mu \mathrm{m}$ filters; d: water outlet and flow meter (right) Source: Schönlau et al. (2020).

It is also important to mention the recent use of new systems (see Fig. 3), like in situ pumps, fractionated cascade filtration and other devices, suitable to collect suspended microplastics in the surface and also in the water column (Abeynayaka et al. 2020; Karlsson et al. 2020; Rist et al. 2020; Schönlau et al. 2020; Setälä et al. 2016). The main improvement of these systems is the more accurate measurement of the water volume filtered. Sediment sampling can be done in intertidal or subtidal areas. Intertidal sampling is generally performed seasonally to account for tide variability. Usually, the sediments are sampled along transects (approx. $100 \mathrm{~m}$ ) set in parallel to the water edge and defined by GPS position. Sampling sites can be 
Table 2. Net types and information collected from manta trawl studies. Comparison of different types of nets used, MP colour categories and units used to report the data; FTIR analysis; and if zooplankton abundance and MP/zooplankton ratio was reported. Adapted from (Herrera et al. 2020).

\begin{tabular}{|c|c|c|c|c|c|c|c|c|c|c|}
\hline Region & Net/size $(\mu \mathrm{m})$ & $\begin{array}{c}\text { MP } \\
\text { colour }\end{array}$ & $\begin{array}{l}\text { MP } \\
\text { type }\end{array}$ & $\begin{array}{l}\text { Sample } \\
\text { sieving }\end{array}$ & $\begin{array}{c}\text { FTIR } \\
\text { analysis }\end{array}$ & Zooplankton & $\begin{array}{c}\text { Report } \\
\text { Items } / \mathrm{km}^{2}\end{array}$ & $\begin{array}{c}\text { Report } \\
\text { Items } / \mathrm{m}^{3} \\
\end{array}$ & $\begin{array}{c}\text { Ratio } \\
\text { MP/Zoo }\end{array}$ & Reference \\
\hline North Pacific Central Gyre & manta 330 & no & yes & yes & no & yes & yes & yes & yes & (Moore et al. 2001) \\
\hline Southern California coastal waters & manta 333 & no & yes & yes & no & yes & no & yes & no & (Moore et al. 2002) \\
\hline Santa Monica Bay, California & manta 333 & no & yes & yes & no & yes & no & yes & no & (Lattin et al. 2004) \\
\hline Southern California Current, Pacific Ocean & manta 505 & no & no & no & no & no & no & yes & no & (Gilfillan et al. 2009) \\
\hline Northeast Bering Sea, Pacific Ocean & Sameoto 505 & no & yes & yes & yes & no & no & yes & no & (Doyle et al. 2011) \\
\hline Southern California, Pacific Ocean & manta 505 & no & yes & yes & yes & no & no & yes & no & (Doyle et al. 2011) \\
\hline North Western Mediterranean Sea & manta 333 & no & no & no & no & yes & yes & no & no & (Collignon et al. 2012) \\
\hline South Pacific subtropical gyre & manta 333 & no & yes & yes & no & no & yes & no & no & (Eriksen et al. 2013) \\
\hline Bay of Calvi, Mediterranean Sea & manta 333 & no & no & yes & no & yes & yes & no & yes & (Collignon et al. 2014) \\
\hline Sardinian Sea, Western Mediterranean & manta 500 & no & no & no & no & no & no & yes & no & (de Lucia et al. 2014) \\
\hline Portuguese coastal waters & neuston 280-335 & no & no & no & yes & yes & no & yes & yes & (Frias et al. 2014) \\
\hline Western Tropical Atlantic Ocean & manta 300 & yes & yes & no & no & no & no & yes & no & (Ivar do Sul et al. 2014) \\
\hline Eastern Pacific Ocean & neuston 333 & no & no & no & no & no & yes & no & no & (Law et al. 2014) \\
\hline Goiana Estuary, Northeast coast of Brazil & plankton 300 & yes & yes & no & no & yes & no & yes & yes & (Lima et al. 2014) \\
\hline Northeast Atlantic Ocean & pump 250 & yes & yes & no & $\begin{array}{c}\text { no, } \\
\text { Raman }\end{array}$ & no & no & yes & no & (Lusher et al. 2014) \\
\hline Southern coast Korea & manta 333 & no & no & yes & yes & no & no & yes & no & (Song et al. 2014) \\
\hline Western Mediterranean Sea & manta 334 & no & yes & no & no & yes & yes & no & no & (Faure et al. 2015) \\
\hline Spanish Northwest coast & manta 335 & no & no & no & no & no & yes & no & no & (Gago et al. 2015) \\
\hline East Asian Seas, Japan & neuston 350 & no & no & no & yes & no & no & yes & no & (Isobe et al. 2015) \\
\hline South East Sea of Korea & manta 330 & no & yes & yes & yes & no & no & yes & no & (Kang et al. 2015) \\
\hline Arctic waters, Norway & manta 333 & yes & yes & no & yes & yes & yes & yes & no & (Lusher et al. 2015) \\
\hline Arctic waters, Norway & pump 250 & yes & yes & no & yes & yes & no & yes & no & (Lusher et al. 2015) \\
\hline Mediterranean Sea & manta 200 & no & yes & no & no & no & yes & no & no & (Cózar et al. 2015) \\
\hline Black Sea & WP2 200 & no & yes & no & no & yes & no & yes & yes & (Aytan et al. 2016) \\
\hline
\end{tabular}




\begin{tabular}{|c|c|c|c|c|c|c|c|c|c|c|}
\hline Mediterranean Sea, near coast & manta 333 & no & no & no & yes & yes, zooscan & yes & no & yes & (Pedrotti et al. 2016) \\
\hline Central and Western Mediterranean Sea & manta 333 & no & no & no & no & no & yes & no & no & (Ruiz-Orejón et al. 2016) \\
\hline Mediterranean Sea & neuston 200 & no & yes & yes & yes & no & yes & yes & no & (Suaria et al. 2016) \\
\hline Northern Gulf of Mexico & neuston 335 & no & yes & no & yes & yes, zooscan & no & yes & yes & (Di Mauro et al. 2017) \\
\hline Pelagos Sanctuary, Western Mediterranean Sea & manta 333 & yes & no & yes & yes & no & yes & no & no & (Fossi et al. 2017) \\
\hline Bay of Brest, France & manta 335 & no & yes & yes & no, Raman & no & no & yes & no & (Frère et al. 2017) \\
\hline Stockholm Archipelago, Baltic Sea & manta 335 & yes & yes & no & yes & no & yes & yes & no & (Gewert et al. 2017) \\
\hline Southern Ocean, Antarctica & manta 350 & no & no & no & yes & no & yes & yes & no & (Isobe et al. 2017) \\
\hline Atlantic Ocean & pump 250 & yes & yes & no & yes & no & no & yes & no & (Kanhai et al. 2017) \\
\hline North-East Atlantic & manta 333 & yes & yes & yes & no & no & yes & yes & no & (Maes et al. 2017) \\
\hline Mediterranean Sea, > $10 \mathrm{~km}$ from coast & manta 333 & no & no & no & yes & yes, zooscan & yes & no & yes & (Pedrotti et al. 2016) \\
\hline Israeli Mediterranean coast & manta 333 & yes & yes & no & no & no & yes & yes & no & (van der Hal et al. 2017) \\
\hline Bornholm Basin, Baltic Sea & Bongo 150 & yes & yes & no & no & no & no & yes & no & (Beer et al. 2018) \\
\hline Pearl River estuary, Hong Kong waters & manta 333 & no & yes & yes & yes & no & yes & yes & no & (Cheung et al. 2018) \\
\hline Guanabara Bay, South-eastern Brazil & neuston 64 & yes & yes & no & yes & yes & yes & yes & no & $\begin{array}{l}\text { (Figueiredo and Vianna } \\
\text { 2018) }\end{array}$ \\
\hline North Western Australia, Indian Ocean & manta 355 & no & no & no & yes & no & no & yes & no & (Kroon et al. 2018) \\
\hline North Western Australia, Indian Ocean & plankton (subsurf) & no & no & no & yes & no & no & yes & no & (Kroon et al. 2018) \\
\hline Chabahar Bay, Gulf of Oman & neuston 333 & yes & yes & yes & yes & no & no & yes & no & (Aliabad et al. 2019) \\
\hline North Atlantic Ocean, Azores & bongo 200 & no & yes & yes & no & yes, zooscan & yes & yes & yes & (Herrera et al. 2020) \\
\hline North Atlantic Ocean, Madeira and Canary Islands & manta 200 & no & yes & yes & no & yes, zooscan & yes & no & yes & (Herrera et al. 2020) \\
\hline Persian Gulf & neuston 300 & yes & yes & no & yes & no & yes & no & no & (Kor and Mehdinia 2020) \\
\hline Baltic Sea and Gulf of Bothnia & Manta 333 & no & no & yes & $\begin{array}{c}\text { NIR- } \\
\text { hyperspectral } \\
\text { imaging }\end{array}$ & no & no & yes & no & (Schönlau et al. 2020) \\
\hline Baltic Sea and Gulf of Bothnia & Pump $\geq 300$ & no & no & no & $\begin{array}{c}\text { NIR- } \\
\text { hyperspectral } \\
\text { imaging }\end{array}$ & no & no & yes & no & (Schönlau et al. 2020) \\
\hline Baltic Sea and Gulf of Bothnia & Pump 50 & no & no & no & $\begin{array}{c}\text { NIR- } \\
\text { hyperspectral } \\
\text { imaging }\end{array}$ & no & no & yes & no & (Schönlau et al. 2020) \\
\hline Nuup Kangerlua, West Greenland & Pump 10 & no & yes & no & yes & no & no & yes & no & (Rist et al. 2020) \\
\hline Nuup Kangerlua, West Greenland & Bongo 300 & no & yes & no & yes & no & no & yes & no & (Rist et al. 2020) \\
\hline
\end{tabular}


distributed along the high tide line, along the low tide line and/or in between. This aspect must be taken into consideration when comparing results. The sampling unit (e.g.: a square of $50 \times 50 \mathrm{~cm}$ ) must be replicated along the transect collecting the first centimetres of sediment. Subtidal sampling is generally performed using grabs or corers being Van Veen grab and Box corers the most usual devices. A Box corer can be used for sediments allowing sampling the first centimetres with minimal impact on sediment integrity. In this case, a replicate (up to six per site) is recommended to check the homogeneity of sampling sites.

\section{Knowledge gaps and research needs}

The methods for MPs sampling vary considerably among studies making it difficult to compare data from different studies (GESAMP 2020). Table 2, adapted from Herrera et al. (2020), presents the different nets, and data categorization from recently published studies (Herrera et al. 2020). The different sampling methods, MPs categories and units used, make impossible the comparison among literature data. A harmonised approach should be established to get relevant and comparable information from sampling campaigns. Data sharing protocols and data platforms at regional level (using the Regional Sea Conventions) and worldwide (like the UN initiative; Global partnership on Marine Litter platform) must include global standards for sampling, identification, and quantification (GESAMP 2020).

One major knowledge gap refers to the need for obtaining information about smaller size ranges. Most studies in the marine environment use mesh sizes above $200 \mu \mathrm{m}$. However, the available data indicated that MPs below current sampling limits might be dominant. Cai et al. (Cai et al. 2018) found that $>80 \%$ of the MPs collected from surface waters of South China Sea were $<200 \mu \mathrm{m}$ (average $145 \mu \mathrm{m}$ ). Enders et al. (Enders et al. 2015) sampled MPs down to sizes of $10 \mu \mathrm{m}$ and concluded that small MPs are ubiquitous in the ocean surface layer, the majority (64\%) of particles being $<40 \mu \mathrm{m}$. Technical developments are necessary to implement standardized procedures for sampling MPs with such small sizes. In some sampling campaigns batteries of plankton nets in series, with mesh size as small as $20 \mu \mathrm{m}$ are already in use, in addition a new plastic-free pumpfilter system has recently been successfully used that allows the collection of MPs down to $10 \mu \mathrm{m}$ (Rist et al. 2020). Concerning sizes in the higher range, standardized cut-offs should be established. Specifically, for marine pollution studies, sampling size ranging from $200 \mu \mathrm{m}$ to $>1 \mathrm{~mm}$ is ideal for comparing samples taken with different types of mesh. It may include 1000, 500, 330 and $200 \mu \mathrm{m}$ opening sizes.

Besides, MPs should be consistently classified according to typology and colour. Typology should include the following categories or others that can be reduced to them: fragments, fibres, lines, pellets, films, foams. RGB colour system can be determined from images using software like ImageJ or similar. Both colour and typology can help to determine the source of pollution or can indicate whether predation is being selective or not. The following nine colour categories are suggested: no colour/white/clear, yellow, orange/brown, red/pink, green, blue, purple, grey/silver, black/dark.

Plankton count is important, as microplastics/plankton ratio is an indicator of the probability of plastic entering the food web through filters feeders. Zooplankton can be quantified using a stereomicroscope and software like Zooprocess (https://sites.google.com/view/piqv/). The identification and counting of the different groups of organisms can be carried out with the ECOTAXA web application (https://ecotaxa.obs-vlfr.fr/). Reports should include the zooplankton abundance in items $/ \mathrm{km}^{2}$ and, preferably, in items $/ \mathrm{m}^{3}$. 
There is an urgent need for information about the fate of smaller size MPs, i.e.: those falling below 100 or $200 \mu \mathrm{m}$ and are currently outside systematic sampling, except for in situ pumping systems. For all sizes, there is a need for agreeing standardized methods to allow comparability from different sources. Standardization is needed in all environmental compartments and in large scale monitoring campaigns. There is a need to record crosscutting data like plankton abundance, proper georeferencing, and environmental conditions. The use of adequate procedures for sample processing and storage should be documented in all studies. This includes the mention to the use (or not) of clean air conditions, the thorough description of controls and any other details that can be relevant for comparing data. A more comprehensive monitoring of freshwater ecosystems is needed as they received far less attention than marine ones, despite the evidence that most plastic litter comes from land sources.

\subsection{Analytical methods}

\section{State of the art}

Large MPs (1-5 mm) are usually identified by optical microscopes (sizes usually $>100 \mu \mathrm{m}$ ) or using the naked eye detection for differentiation from non-plastic materials. This approach allows evaluating colour, shape, size, and number of plastic particles and, accordingly, several guidelines have been reported for harmonizing the visual identification of MP particles (Lv et al. 2020). Dyes (e.g.: fluorescent dye Nile Red) are used sometimes to improve discrimination. However, visual identification is not usually accurate enough for scientific and monitoring purposes and other techniques are required. High-throughput alternatives based on specific equipment used for zooplankton (ZooScan or FlowCam), flow cytometry or by a high-resolution scanner in combination with automatic image analysis or computer vision have been recently developed to count and classify MPs into different visual classes, thereby reducing analysis time and cost (e.g.: SMACC, which is freely distributed by EOMAR group from University of Las Palmas de Gran Canaria) (Lorenzo-Navarro et al. 2020). In any case, and even if high-throughput techniques are used, the analysis of plastic pollutants is complex, expensive, and time-consuming. Therefore, there is a need for establishing the size of subsample to be analysed based on robust statistical criteria, which is a caution very rarely addressed in the literature. Relatively simple statistics can be used to assess the accuracy of results within a certain error margin (Kedzierski et al. 2019).

Analytical methods based on spectroscopic techniques such as Fourier transform infrared spectroscopy (FTIR) or Raman spectroscopy allow non-destructive chemical characterization and are commonly used to accurately identify plastic polymers (and sometimes additives) over a wide range of particle sizes (Xu et al. 2019). These techniques require a small amount of sample although they normally involve careful spectra gathering and long analysis time. Larger particles can be analysed by attenuated total reflectance (ATR) FTIR spectroscopy with high speed and accuracy $(200 \mu \mathrm{m}-5000 \mu \mathrm{m})$. Depending on the setup of the application, small particles can also be measured only down to the range of $20 \mu \mathrm{m}$ (reflectance or transmittance modes) due to the diffraction limit (Lv et al. 2020). Recently, the combination of FTIR with an IR microscope (single point, focal plane array or linear array) has emerged as micro-FTIR for the characterization of samples with sizes down to $10 \mu \mathrm{m}$ (Löder et al. 2015). Raman spectroscopy can detect small plastic particles down to $1 \mu \mathrm{m}$ and using micro-Raman even smaller sizes could be achieved, although limited by fluorescence from some polymers or from biogenic materials. In addition, aged and weathered plastics must be included in the spectral libraries used for identifying environmental samples. An important drawback is that micro-spectroscopic identification is a very timeconsuming task, especially when analysing the entire sample and smaller particle size ranges in complex environmental samples. 
To cope with these limitations, automatic image software based on library search and chemometric analyses have been developed that reduce working time and cost sometimes using freeware software tools (e.g.: siMPle, developed by Aalborg University and Alfred Wegener Institute) (Meyns et al. 2019). Lately, hyperspectral imaging (HSI) is used to characterize larger MPs (> 200$300 \mu \mathrm{m})$. It produces 3D hyperspectral image hypercube, which contains spatial and spectral information such as morphological features and chemical characteristics of the analyte. The main drawback of HSI is data processing complexity because users must develop customized algorithms and models to extract information (Fu et al. 2020).

In contrast to spectroscopic techniques, the thermal analysis is being increasingly used for MP characterization, which includes pyrolysis gas chromatography-mass spectrometry (Py-GC-MS), thermogravimetric analysis (TGA), hyphenated TGA such as TGA-mass spectrometry (TGA-MS), TGA-thermal desorption-gas chromatography-mass spectrometry (TGA-TD-GC-MS), TGAdifferential scanning calorimetry (DSC) (Peñalver et al. 2020). These methods give information about chemical composition but not about size, shape, or number of MPs in each given sample. Besides, they are destructive techniques. One of the main advantages of Py-GC-MS is the possibility of the chemical characterization of polymer and organic additives in the same analysis (Fischer and Scholz-Böttcher 2017; Fries et al. 2013). Py-GC-MS does not usually require any pretreatment and only needs a very small amount of sample (in the low $\mathrm{mg}$ or $\mu \mathrm{g}$ range and even only one particle). X-Ray fluorescence can assess additives or adsorbed metals, while scanning electron microscopy reveals information on morphology and composition of MPs. These are complementary techniques with generally high cost (Fries et al. 2013).

\section{Knowledge gaps and research needs}

There are still no harmonised analytical methods for quantifying and determining the occurrence and composition of M/NPs in environmental samples. For most environmental applications, the methods currently applied for the detection, characterization, and identification of M/NPs are complex, tedious, and time-consuming, and difficult to automate. All of them suffer from matrix effects and require controversial sample pretreatments. There are issues relating to the use of standard metrics, pretreatment and separation methods and there is also an urgent need to improve rapid and reliable analytical methods, particularly for small size MPs as quantitative data for particles with a size smaller than c.a. $50 \mu \mathrm{m}$ are scarce in the literature. There is an important difficulty derived from the huge variety of polymers and additives that can be included in MPs such as plasticizers, flame retardants, pigments, stabilizers, and many others, that have been used to modify their properties and characteristics (Hermabessiere et al. 2017). Additionally, the weathering of plastics can modify their composition or some of their characteristics making it difficult to detect them in environmental matrices (Fernández-González et al. 2021; Jahnke et al. 2012).

A first non-solved issue is the metrics used to report "plastics", which is closely related to the analytical methods required. One of the most usual units found in published articles is items of plastic per unit of volume, weight or similar of the environmental matrix (i.e.: items $/ \mathrm{kg}$ sediment). This approach requires methods that individually separate and identify every single item. This type of methodology is extremely time-consuming, impossible to apply to NPs and, to some extent, dependant on the analytical operator and, for brittle materials, a possible source of errors (if the items break in two pieces the result would be the double number of items). Another approach, more in line with what is normally done in the analytical quantification of pollutants in the environment is to report the results as the weight of plastic per weight or volume of the environmental matrix (i.e.: $\mathrm{mg} / \mathrm{kg}$ sediment). This approach is applicable to M/NPs and would be probably more accurate and lead to more comparable results with the drawback of the difficulty to separately quantify the different plastics components of environmental mixtures. The need to clearly define what to 
measure and how to report data is critical if the results are to be used for risk assessment and included regulatory frameworks such as the Marine Strategy Framework Directive or, in the future, the Water Framework Directive.

Depending on the sample to be analysed, a suitable pretreatment might be necessary. At some stage, floatation, as a density fractionation method, is generally required followed by suitable filtration. However, there is wide variability in the type of solutions in which floatation can be developed: saturated solutions of $\mathrm{NaCl}$ (the cheapest and most common), $\mathrm{NaI}, \mathrm{NaBr}, \mathrm{ZnCl}_{2}, \mathrm{ZnBr}_{2}, \mathrm{CaCl}_{2}$, sodium or lithium metatungstate, among others (Gong and Xie 2020; Li et al. 2020; Miller et al. 2017; Prata et al. 2019a; Silva et al. 2018). There is a clear need to establish a floatation protocol, since the use of a certain type of solution determines the plastics that can be separated. For this purpose, apart from the density of the floating solution and polymers, the toxicity of the salts, their cost as well as their possible interaction with specific materials ( $\mathrm{NaI}$ reacts with cellulose filters) should be considered. Besides, for MPs of very small sizes (typically $<10 \mu \mathrm{m}$ ) floatation may not be suitable, while the separation of fibres by floatation is also difficult (Miller et al. 2017). An important issue regarding floatation is that its automation remains a challenge.

The removal of organic matter is another important step in samples from soils, sediments, sewage sludge, biosamples, and many others. Organic matter removal can be achieved with acid $\left(\mathrm{HNO}_{3}\right.$, $\mathrm{H}_{2} \mathrm{SO}_{4}, \mathrm{HClO}_{4}$ or mixtures of them) or basic (i.e. $\left.\mathrm{NaOH}, \mathrm{KOH}\right)$ treatments, oxidizing agents $\left(\mathrm{H}_{2} \mathrm{O}_{2}\right.$ with or without $\mathrm{Fe}(\mathrm{II})$ as catalyser-Fenton's reagent) or enzymatic digestion (using proteolytic enzymes like trypsin, papain, pepsin or collagenase) at different temperatures and times, without a clear harmonized procedure (Bretas Alvim et al. 2020; Miller et al. 2017; Prata et al. 2019a; Primpke et al. 2020). It should be considered that a complete elimination of organic matter might not always be possible. Besides, chemical and structural integrity of the polymer, which is an organic compound itself, may be affected, a fact that should be carefully evaluated (Munno et al. 2018; Prata et al. 2019a). Aggressive pretreatments can be strongly influenced by the ageing of plastics specimens, as well as their composition and size.

Concerning fibres, and, in general, MPs of small size (i.e. $<300 \mu \mathrm{m})$, it is also frequent to incubate them in a dye solution like, for example, Nile Red (which is also fluorescent) or Rose Bengal (Prata et al. 2019a; Prata et al. 2019b), once they are separated from the sample matrix. This is normally done by immersing the filtration membranes into the dye solution (Primpke et al. 2020). Staining facilitates the visual identification in different ways. For example, Nile Red will improve their observation by fluorescence or any other imaging technique while Rose Bengal will not normally stain MPs but natural particles (Bretas Alvim et al. 2020; Primpke et al. 2020). Despite the benefits achieved by dye staining, this method alone is a non-specific approach that may yield false positives. Another important issue regarding sample pretreatment is the composition of the filters to be used for the recovery of MPs from liquid samples or from the supernatant of the density separation, especially if they are directly used for further spectroscopic analysis since their compatibility should be considered (i.e. with FTIR or Raman).

There is a lack of relevant information on the instrumental setup required to replicate the environmental studies undergone (e.g.: up to $25 \%$ of the published papers do not reported relevant instrumental operational details); therefore, some MPs identifications might be compromised (Andrade et al. 2020). In addition, statistical assessment of sample-associated errors should be systematically addressed. The fraction of sample derived to micro-FTIR or other characterization techniques must not be arbitrary and accuracy, representing half-width of the confidence interval should be routinely reported. Standardized analytical procedures and more efficient analysis workflow of environmental samples should be carried out regarding sizes, shapes and material identity focussing on the development of automatized systems to avoid biases in plastic 
identification and providing a reliable estimation of environmental contamination from MPs (Campanale et al. 2020).

Appropriate quality assurance/quality control (QA/QC) procedures are required to improve data reliability. Thus, cross-contamination/procedural blanks should be routinely performed during all steps of the analytical procedure, especially when measuring small fragments and fibres to assess the representativity of results. Besides, the results of procedural blanks should be reported. The recovery rates of the analytical procedure using spiked samples are also relevant to assess the accuracy of the selected methodology, avoiding the risk of under- or overestimation of the reported MPs. The validation of the analytical methods for measurements of MPs is hampered by a general lack of standards and reference materials (Seghers et al. 2021). In fact, it is particularly challenging to prepare reference materials able to mimic the MPs found in environmental samples. However, there is an urgent need to develop such standards to achieve reliable monitoring of MP contamination. In addition, interlaboratory comparison exercises are also required to detect potential biases, uncertainties, and other sources of error, and to demonstrate proficiency and competence. As recent examples, the European Commission's Joint Research Centre (JRC) has been involved in the preparation of a reference material for MPs (PET) in water and proficiency tests on MPs in water (PET), and in sediments (PE). QUASIMEME/NORMAN organized an international laboratory intercomparison exercise to determine the polymer type and number or mass of polymer particles in different samples, which revealed an urgent need for harmonization (van Mourik et al. 2021). These challenging analytical progresses will contribute to improve the reliability of MP analysis to support monitoring programmes, research and decision-making.

An even greater challenge is the identification of smaller-sized M/NPs, especially for complex matrices and if particles are affected by plastic weathering that may cause misclassification. All techniques generally available have a particle size limit of a few micrometres; consequently, new methods must be developed to cover the smaller sizes of MPs $(<10 \mu \mathrm{m})$ and the nanometre range $(<1000 \mathrm{~nm})$. Recently, promising techniques widely used for characterizing nanomaterials have been applied to small MPs. Field flow fractionation (single-particle mode of inductively coupled plasma-mass spectrometry) allow active particle separations. Hydrodynamic chromatography, a solution-phase liquid chromatographic separation method, is advantageous for particle size determination in the range from $10 \mathrm{~nm}$ to $1 \mu \mathrm{m}$. For physicochemical quantification, dynamic light scattering (DLS) and nanoparticle tracking analysis (NTA) is useful for the hydrodynamic size and zeta potential measurements of M/NPs. Recently, atomic force microscopy (AFM) is an emerging nanoscale characterization technique of materials. Besides morphological information, chemical properties are also achieved in combination with spectroscopic IR or Raman IR techniques (Dominguez et al. 2014). So far, there have been a very limited number of studies using hybrid AFM techniques (AFM/IR or AFM/Raman) to detect and characterize M/NPs (Fu et al. 2020). Raman spectroscopy can also be combined with SEM allowing a spatial resolution down to several hundred of nanometres (Zhang et al. 2020). However, the techniques for detecting NPs are still complex and difficult to apply to environmental samples. There is an urgent need to develop and implement more precise, more reliable and less time-consuming methodologies for the identification and quantification of MPs (particularly small size MPs) and NPs in environmental matrices.

\subsection{Additives and other non-intentionally added substances}

\section{State of the art}

Commercial plastics are not pure polymers. They include many additives to improve their processability and their properties that include a wide series of different chemicals and materials: 
fillers, plasticizers, colorants, stabilizers, flame retardants, compatibilizers, among others, which are found in different proportions in the formulation of plastic materials (Ambrogi et al. 2017). Most additives are included at levels of very low percent by weight, although some of them, like flame retardants or plasticizers, may reach much higher values (Hahladakis et al. 2018). It is welldocumented that the additives found in plastics have the potential to contaminate the environment. Inorganic substances like metals become easily leached, while organic compounds are released directly or as degradation products after photochemical reaction (Bandow et al. 2017). In contact with water, additives migrate to the aquatic media (Koelmans et al. 2014; Mato et al. 2001; Romera-Castillo et al. 2018). The migration of additives in food contact plastic materials poses an additional issue to human health and food quality if transferred beyond certain limits (Bhunia et al. 2013). Noteworthy, some additives, like antioxidants, ultraviolet (UV) absorbers and biological preservatives, are responsible for enhanced persistence of many plastics that degrade very slowly under environmental conditions (Hahladakis et al. 2018). Besides intentionally added chemicals, other substances, like mono- and oligomers from the plastic structure can be released threatening the environment (Amamiya et al. 2019; Saido et al. 2014). As an example, unreacted styrene from polystyrene (PS) packaging materials has been detected in different matrices (Arvanitoyannis and Bosnea 2004). The transfer of PET oligomers to drinking water has also been described (Hoppe et al. 2017). This issue has been dealt within the context of food safety, but, as non-intentionally added substances, there is also a concern associated to their leaching to the environment (Hoppe et al. 2016).

\section{Knowledge gaps and research needs}

The risk assessment of additives faces an important problem of lack of information about the chemical nature of the additives themselves and their concentrations in plastic materials because of the secrecy associated with proprietary formulations. Some information is available, but much more is needed, about additives and their potential toxicity when incorporated to plastic products. Significant efforts have been made in the field of plastic packaging. A database has been created that includes near one thousand chemicals plus several more thousands possibly associated with plastic packaging. Some of them are known by posing a significant risk to human health and to the environment according to ECHA, including endocrine-disrupting chemicals and persistent and bioaccumulative compounds (Groh et al. 2019). The issue is not only the enormous number of different chemicals in use but the lack of transparency and incompleteness of publicly available information on the use of many substances. The fact that many plastic objects are produced in countries with limited access to the information does not help. Obviously, their long-term toxicity and possible mixture effects are essentially unknown except for some of the most hazardous chemicals.

The environmental conditions affect the intensity of chemical migration from the plastic to the aquatic media. Turbulence was found to enhance plastic leaching especially of those additives less soluble in water (e.g., phthalates or Irgafos ${ }^{\circledR} 168$ ) in comparison with those with higher solubility (e.g.: BPA) (Suhrhoff and Scholz-Böttcher 2016). Other variables, such as salinity, affect differently the intensity of the plastic leaching depending on the intrinsic nature of the additive (Suhrhoff and Scholz-Böttcher 2016). The effect of photochemical ageing on the release of additives and depolymerization fragments has been studied but results are not yet conclusive (Lee et al. 2020; Romera-Castillo et al. 2018; Suhrhoff and Scholz-Böttcher 2016; Zhu et al. 2020). The degradation stage of the plastic can also affect the leaching rate and its toxicity to marine fauna (Bejgarn et al. 2015; Saido et al. 2014).

There is also a considerable lack of knowledge about the possible degradation products originated from additives under environmental conditions. The analyses required to trace the huge amount of 
oxidation, photodegradation and biotransformation products that can be originated from plastic additives are highly challenging. The identification of additives and their degradation products is a very complex issue due to the large number of different types of chemicals used, the relatively high molecular weight of many additives, their presence in mixtures and their inclusion in complex matrices, particularly when dealing with food transfer chemicals (Blázquez-Blázquez et al. 2020). As for the environmental fate of plastic debris, additives received much less attention compared with food contact materials. There is a need to characterize the additives associated with the MPs detected in environmental samples. Non-target screening analysis and toxicity studies are required to assess the risk of additives leaching from plastic debris. The transfer of additives to the food chain upon MPs ingestion, and their effect on freshwater and marine organisms are largely unknown. The possible formation of toxic degradation products from additives upon oxidation or photochemical processes is another complex issue that requires attention. The degradation pattern and leaching of dissolved organic carbon from biodegradable polymers should be clarified, as up to date, the environmental impact of their degradation products is poorly understood. In addition, there is scarce information about the processes that such additives suffer when recycling polymers or the additives released in the environment from recycled polymers. All of these are key issues to promote more sustainable and non-toxic reusable products reducing the impact of plastics on the environment.

\subsection{Sorption of chemicals}

\section{State of the art}

Plastic has the capacity to absorb and desorb organic compounds, such as persistent or emerging organic pollutants (Rodrigues et al. 2019; Wang et al. 2018). The available data suggest that certain hydrophobic pollutants adsorb onto the surface of MPs reaching a concentration much higher than in surrounding water (Mato et al. 2001). Field campaigns detected aromatic hydrocarbons, polychlorinated biphenyls, organochlorine pesticides, brominated diphenyl ethers and organophosphorus flame retardants among other pollutants in MPs from marine environments and sediments (Camacho et al. 2019). Despite the ample evidence that MPs accumulate persistent organic pollutants, this does not result in MPs being important for their global dispersion and there is scant evidence that MPs are an important transfer vector for bioaccumulative chemicals (Lohmann 2017). Physicochemical studies suggested that the adsorption of hydrophobic pollutants would be insufficient to increase the exposure to toxic substances in the marine environment (Koelmans et al. 2016). Gouin et al. used thermodynamic calculations to show that the importance of MPs as a carrier of hydrophobic substances is probably limited in marine environments because the partition of pollutants among plastic, air and water would not result in significant adsorbed amounts even for volumes of plastic orders of magnitude above current values (Gouin et al. 2011). Recent experimental work confirmed the theoretical hypotheses showing that the presence of MPs (polyethylene particles $150 \mu \mathrm{m}$ diameter) does not increase the bioconcentration of lipophilic chemicals in fish (Danio rerio) or marine plankton (Beiras et al. 2019; Schell et al. 2020a). However, limited studies are available to evaluate possible different patterns in organisms with different physiological characteristics (e.g.: invertebrates) and in different environmental matrices (e.g.: soil or sediments). Therefore, the role of plastics as a vector of organic pollutants to biological organisms is still unclear. The concentration of certain chemicals such as contaminants of emerging concern or persistent pollutants is particularly high in inland waters, close to zones of intensive agriculture, industrial placements or near the discharge of wastewater treatment plants. Adsorbed chemicals might be released when the conditions of the external medium changes, such as inside the animal guts (e.g. pH conditions). Compounds eventually translocated to organs or tissues may induce damage and move through the trophic web until humans. 


\section{Knowledge gaps and research needs}

The relative importance of plastics as a vector in the transport of chemical contaminants to biota is influenced by several factors like polymer characteristics, material ageing, chemical environment, and residence time in the organism when ingested, among others. Although experimental and modelling evidence suggests that plastics would not represent an important pathway for the transfer of sorbed chemicals, more work is needed to assess this fact across a wider range of organisms (Bakir et al. 2016). It is a fact that plastics can sorb pollutants from the environment relatively quickly and their concentration on their surface or dissolved in the glassy phase can become orders of magnitude higher than in the surrounding aquatic environment (León et al. 2018; Mato et al. 2001). If sorbed chemicals desorb upon ingestion this could provide a route for transferring pollutants to biota (Teuten et al. 2007). The relative importance of this pathway has yet to be fully evaluated in freshwater, soils, and sediments. Plastics from intensive agriculture or in contact with wastewater discharges may be exposed to high concentration of toxics and, therefore, cause a higher carrier effect than that of marine debris.

Sediments and soil have been recognized as a major sink of MPs, probably one order of magnitude higher than oceans (Tourinho et al. 2019). There is a need to extend studies to them as well as including relevant organisms such as soil invertebrates. The effect of MP ageing should also be considered. The interaction of pollutants and microplastics changes from hydrophobic interaction to hydrogen bonding as hydrophilic moieties appear upon oxidation and photo-oxidation. The interaction with polar and semipolar compounds should be emphasized including antibiotics, new pesticides, and other compounds of emerging concern (CEC).

\subsection{Interaction with microorganisms}

\section{State of the art}

Once in natural environments, plastics are easily colonized by different types of microorganisms, including bacteria, archaea and eukaryotes such as fungi, diatoms and protists (Kettner et al. 2017; McCormick et al. 2016). The term "plastisphere", first coined by Zettler et al. identifies plastic as a new niche or habitat for microorganisms (Amaral-Zettler et al. 2020; Zettler et al. 2013). Advanced DNA sequencing protocols (metabarcoding analyses as well as shotgun metagenomics; generally known as next-generation sequencing, NGS, techniques) facilitated the knowledge of the diversity of microorganisms forming biofilms on different types of polymers and have allowed comparison with those free-living in the water column or attached to the sediments (Jacquin et al. 2019). Most studies about plastic-colonizing microorganisms have been made in marine environments and only a few have targeted freshwater environments (Hoellein et al. 2014; McCormick et al. 2016). The experimental approach of reported studies is highly variable. Some are based on the in situ sampling of plastics or MPs in aquatic environments (Bryant et al. 2016; De Tender et al. 2017; Lee et al. 2014), while others selected different types of artificial polymers and sizes and incubated them under controlled experimental conditions using microcosms (Ogonowski et al. 2018).

Biodegradable plastics have also been found more easily colonisable than non-biodegradable ones (Dussud et al. 2018). Most studies describe that location (in situ environment), rather than polymer type, determines microbial community on plastic biofilms, but data are still scarce to provide general trends.

Biofilm formation in any matrix (including plastics) involves a series of phases from initial colonization to maturation. Early attachment by pioneer microorganisms is usually facilitated by the formation of a surface organic layer on the substrate. At this stage, physical properties of the material such as roughness, charge, density, mechanical stability, or hydrophobicity may play 
crucial roles. Subsequent production of extracellular polymeric substances determines the capacity of biofilms to grow and to establish cell-cell interactions, which is an evolutionary strategy to survive in unfavourable environments (Flemming et al. 2007). Usually, during the maturation phase, a succession of new settlers occurs and finally the biofilm disperses, and the free microbes look for new niches to be established. Several studies have followed the dynamics of the formation of biofilms on plastics showing that biofilm formation was stable enough to reconstruct temporal dynamics allowing the identification of indicator species of the different stages of biofilm formation (De Tender et al. 2017). Some results reported significant changes in microbial diversity depending on polymer type (De Tender et al. 2017; Ogonowski et al. 2018; Webb et al. 2009). It was suggested that differences between substrates may be stronger during early stages of biofilm formation (Oberbeckmann et al. 2016). In this context, most studies have examined microbial colonization in mid to long-term experiments, while early microbial colonization has seldom been studied although it is a critical phase for biofilm conditioning. A recent study characterized bacterial communities in the early stage of biofilm formation on seven different types of MPs (including biodegradable as well as non-biodegradable ones) deployed in two different WWTPs effluents (Martínez-Campos et al. 2021). An early colonization phase MPs-core microbiome was identified. Furthermore, linear discriminant analysis effect size analysis (LEfSe) allowed identifying core microbiomes specific for each type of polymer suggesting that each type might select early attachment of bacteria.

An important issue of microbial colonization is that plastics may be first colonized by taxa that can degrade plastic polymers to some extent. For example, different species of Pseudomonas which have been found on plastics have been associated with the degradation of PE, polypropylene (PP) or poly(vinyl chloride) (PVC) (McCormick et al. 2014; McCormick et al. 2016). Oberbeckmann et al. (2016) also found PET-colonizing taxa that might degrade the polymers they colonize such as taxa belonging to the family Rhodobacteraceae which one of its members Rhodococcues rubers has been reported to degrade the less stable substrate PE (Oberbeckmann et al. 2016). Martinez-Campos et al. reported in their study of early bacterial colonizers on MPs deployed in WWTP effluents that genera Pseudomonas, Variovorax, Aquabacterium or Acidovorax, which have species able to metabolize recalcitrant substances including plastics, were dominant in MPs (Martínez-Campos et al. 2021). It is interesting that biodegradable MPs were also enriched on these potential degrading taxa (Aquabacterium and Pseudomonas in PHB and Variovorax in PCL). In fact, taxa specialized in complex carbon degradation (including some recalcitrant compounds) have also been found (Bryant et al. 2016). This raises the question as to whether these colonizers might be involved in plastic or other organic compounds degradation as a source of carbon for their growth and metabolism. It is important to note that conventional plastics have been designed to be intrinsically persistent, not only because of the nature of their polymeric backbone, but also because they are blended with stabilizers that limit oxidative or photochemical degradation. Therefore, the biodegradation of 'nonbiodegradable' plastics is difficult, which is the reason they constitute a group of persistent organic pollutants. Oxo-degradable plastics, which contain additives that accelerate oxidation processes, have been recently banned in the EU (Directive 2019/904).

NGS analyses have underpinned that MPs might host pathogens within attached microorganisms and thus, might act as vectors to distribute them in their movement through aquatic ecosystems. Sequences belonging to potential pathogens such as Vibrio and Arcobacter spp. have been identified in MPs in marine as well as freshwater environments (Amaral-Zettler et al. 2015; Harrison et al. 2014; Martínez-Campos et al. 2021). Campylobacteraceae, a family that includes several taxa associated with human gastrointestinal infections, and potential fish pathogens like Aeromonas, have been identified on MPs in an urban river (McCormick et al. 2014). It is remarkable the finding that biodegradable MPs such as PLA, PHB and PCL showed a significant abundance of genera with potential pathogenic members such as Pseudomonas, Comamonas, 
Aeromonas and Vibrio; this might be of concern since the capacity of the MPs to act as vector of potentially pathogenic taxa may be facilitated by their biodegradability (Martínez-Campos et al. 2021). In addition, viruses, such as the SARS-CoV-2, which is the coronavirus responsible for the COVID-19 pandemic, is of concern given that the virus may remain active during several days on plastics (van Doremalen et al. 2020). The material used to be protected from the pandemic, in particular facemasks, are usually made of PP and PA and are being disposed carelessly in the environment. Thus, they are becoming a real environmental problem because the virus has already been found in wastewaters (Chavarria-Miró et al. 2020) and in other countries.

There is also a growing concern that MPs and plastics in general may be reservoirs of antibiotic resistance bacteria (ARB) and cognate antibiotic resistance genes (ARG) (Laganà et al. 2019; Wang et al. 2020; Yang et al. 2019). ARB may survive in the presence of one or more antibiotics and that might be a potential threat for human health. In addition, ARGs are carried usually on broad-host range plasmids or other mobile elements that may be potentially transferred by horizontal gene transfer to nearby receptors, which may contribute, to global spread of antibiotic resistance (Sultan et al. 2018; Wang et al. 2020). It was recently reported that MPs could concentrate ARGs such as sulI, tetA, tetC, tet $X$, ermE and ermF from the surrounding water (Martínez-Campos et al. 2021; Wang et al. 2020).

\section{Knowledge gaps and research needs}

The colonization of plastic substrates by microorganisms is still largely unknown. Specific in situ environments might select the indicator species and early-stage development of plastisphere communities should be studied not only in marine but also in soil and freshwater habitats. An important issue seldom tackled is whether there are changes in community composition along with the transport from WWTP to rivers and to the ocean. Several studies have found that geography and season are the main factors in shaping microbial communities in plastics (Lee et al. 2014) (Oberbeckmann et al. 2014). The transport of non-indigenous species or pathogens (like bacteria or viruses) using plastic debris as transport mechanism should be compared to natural materials. The stability and physical properties of plastics may favour the attachment and transport of mobile and sessile species to new areas. In this context, MPs have been found in remote regions such as in the Arctic in deep-sea sediments (Bergmann et al. 2017), seawater (Cincinelli et al. 2017; Cózar et al. 2017; Lusher et al. 2015) and sea ice (Obbard et al. 2014; Peeken et al. 2018), and recently in a freshwater lake (González-Pleiter et al. 2020). The colonization of MPs from remote regions has not been addressed yet. An important knowledge gap exists about the potential of MPs to act as vectors of ARBs/ARGs in remote locations because they would shed light on the global issue of antibiotic resistance (Hendriksen et al. 2019; Pärnänen et al. 2019).

Only a few studies about microbial colonization of plastic wastes have been carried out on soil environments, albeit recent evidence indicate that plastics are abundant in soils. The recent study of Puglisi et al. confirms the novel hypothesis that different plastics host different bacterial communities, and that their structure can be correlated with the physico-chemical properties of the plastics, particularly their degradation degree (Puglisi et al. 2019). The most degraded polyethylene films were found to host a bacterial community similar to the surrounding soil. Meanwhile the study of Zhang et al. concluded that the bacterial communities colonizing microplastics were significantly different in structure from those in the surrounding soil, plant litter and macroplastics (Zhang et al. 2019a).

Overall, the role of MPs as a new niche for microorganisms is not well understood. It is a new microbial habitat that might already be performing a role at the ecological level. MPs may contribute to disperse microorganisms even to remote areas or to host pathogens. This could include 
ARBs/ARGs possibly posing an important issue to human health and the environment. Colonized MPs may alter the feeding behaviour of many aquatic organisms that may feed on them. Further research is needed on the potential transfer of pathogens or ARGs to the aquatic trophic web. Attention must be paid to microbial assemblages that may be involved in polymer degradation and metabolism of xenobiotics, including biodegradable plastics. This merits further research as new degradation pathways may be discovered.

\subsection{Degradation and fate of microplastics}

\section{State of the art}

The breakdown of plastic is known to be triggered by environmental factors like light, oxygen, temperature and mechanical erosion. Recently, it has been demonstrated that some aquatic invertebrates can also contribute to MP breakdown (Mateos-Cárdenas et al. 2020). Mineralization as the final stage of polymer degradation takes a very long time. Polyolefins, which are the most abundant polymers in marine samples, may persist even hundreds of years exposed to hydrolysis and photo-oxidation conditions (Barnes et al. 2009). Several studies showed how the abiotic ageing of polymers leads to their fragmentation in smaller pieces (Gewert et al. 2015; Kalogerakis et al. 2017). Surface cracking makes the rest of polymeric material more prone to degradation, while the mechanical properties related to the fabrication process might play a major role in the fragmentation propagation of cracks and eventually in the disintegration of specimens. The data indicate that fragments are generated when cracking lines converge, so cracking is key to predict the number and size of the fragments produced from a given material (Julienne et al. 2019). The biodegradation of 'non-biodegradable' MPs does exist, but it is very slow as most plastics are very resistant to microorganisms because high molecular weight and hydrophobic surfaces make them inaccessible to microbial enzymes. Some studies identified strains capable of certain biodegradation of conventional polymers, but at a very slow rate (Skariyachan et al. 2017). Multiomics and synthetic microbial communities have been explored to enhance plastic biodegradation with a certain degree of success (Jaiswal et al. 2020). Many fungi are able to degrade complex carbon polymers such as lignin, which might imply that they can also degrade plastics. Lignin-degrading enzymes such as oxidases, laccases and peroxidases have been reported as responsible for the degradation of plastic polymers by fungi (Shah et al. 2007). Most reports describe fungi able to degrade Polyurethane (PU) by extracellular polyurethanases (Russell et al. 2011). Brunner et al. found several fungi growing on plastic debris floating in the shoreline, which were able to degrade PU (Brunner et al. 2018). The capacity of fungi to degrade $P E$ is controversial although that capability has been reported (Ojha et al. 2017). Regarding biodegradable plastics, fungal depolymerases have been found capable to degrade PHB films (Panagiotidou et al. 2014).

Most polymeric molecules are chemically (and toxicologically) inert, but the same does not stand for their degradation products. Plastics can be broken down into smaller pieces and the smaller they are, the higher their surface to volume ratio, with more plastic surface potentially leaching. There are more than 250,000 tons of plastics floating in the ocean exposed to UV radiation and oxygen degradation, which are the main abiotic factors responsible for plastic degradation and leaching (Andrady 2011; Eriksen et al. 2014). Up to 23,600 tons of dissolved organic carbon (DOC) can be released from plastic reaching the ocean every year (Romera-Castillo et al. 2018). About $7 \%$ of the plastic weight can be lost in form of DOC under UV irradiation (Zhu et al. 2020). The leached material mainly consists of low molecular weight compounds $(<350 \mathrm{Da})$ and its release is enhanced by UV radiation (Lee et al. 2020). It has been shown that leached compounds may alter the marine food web by stimulating marine bacterial growth (Romera-Castillo et al. 2018; Zhu et al. 2020). It has also been shown that they can impair the photosynthetic capacity and growth of cyanobacteria (Tetu et al. 2019). 


\section{Knowledge gaps and research needs}

Fracture behaviour and the propagation of cracks in aged plastics require further studies. The parameters governing plastic fragmentation have not been completely identified and there are great difficulties to monitor fragmentation patterns in real environments. Therefore, artificial weathering protocols should be developed to clarify fragmentation kinetics (Andrade et al. 2019; Julienne et al. 2019). It is necessary to gain information about the influence of abiotic and biotic factors in the fragmentation process of plastic debris to model the number of small pieces of MPs and NPs in environmental compartments, which is a major question still open in M/NPs research (Koelmans et al. 2017b).

The degradation patterns (time, intermediate products) of different types of polymers in different environmental conditions is not well understood in terms of DOC generation and should be better investigated. The biodegradation of conventional plastics by microorganisms is poorly known, in particular regarding the isolation of depolymerization enzymes and their mechanism of action. Another poorly known but relevant issue is the fate of non-traditional plastic polymers, the socalled biodegradable polymers, which include their subclass of compostable plastics. Their actual degradation patterns, as well as the environmental impact of intermediate products, should be thoroughly investigated. The available data point towards a non-negligible environmental impact of MPs derived from the biodegradation of bio-degradable plastics (González-Pleiter et al. 2019). This is an aspect of high economic and social relevance and should be thoroughly investigated. Plastic leachates can also have consequences in human health after interacting with other chemicals. For instance, the chlorine often applied in WWTP as a disinfectant can react with the organic compounds migrated from plastic to form toxic disinfection by-products such as trihalomethanes (Lee et al. 2020).

\subsection{Direct adverse effects of microplastics}

\section{State of the art}

One of the major properties of most plastic polymers is their lack of chemical reactivity. Moreover, MPs in the size range of a few tens of $\mu \mathrm{m}$ up to a few $\mathrm{mm}$ are too large to be capable to cross cell membranes and enter cells. Therefore, the adverse effects of MPs on living organisms, if only the effects of particles are considered, excluding chemical additives that may be present in some formulations (Section 3.4), cannot be considered toxic effects. Indeed, toxicity is the reaction, inside of the cell, of a chemical substance with a chemical cellular receptor (specific toxicity) or with the general chemical environment of the cell (non-specific or narcotic-type toxicity) (Verhaar et al. 1992).

MPs ingested by higher organisms pass through the digestive tract and can be eliminated through faeces. Possibly, a different pathway may occur with very small size MPs (a few $\mu \mathrm{m}$ ) or NPs (Sections 3.9 and 3.10). The ingestion of MPs may produce physical injuries, inducing inflammation and stress, or it may result in a blockage of the gut and subsequent reduced energy intake or respiration. MPs may also produce behavioural effects such as reduction of feeding efficiency (Besseling et al. 2017; Cole et al. 2015; de Sá et al. 2015).

In recent years. a huge amount of information has been produced on the adverse effects of MPs on aquatic (freshwater and seawater) and terrestrial organisms. Several types of organisms have been tested covering various taxonomic groups (e.g.: crustaceans, insects, molluscs, annelids, fish), ecological role and feed habit (e.g.: filter feeders, grazers, predators), habitats (e.g.: planktonic, 
benthonic, sediment-dwelling, soil organisms). Short term (e.g.: mortality) and long-term (e.g. growth, reproduction) endpoints have been addressed. Tests have been performed using various types of test materials (micro-beads, fibres, tyre debris) of different size, also in relation to the size of tested animals, shape, and chemical composition (de Sá et al. 2018) (Kögel et al. 2020). In most studies tests have been designed to provide ( $\mathrm{LC}_{50}$ results) with concentrations that are beyond the environmentally realistic range (Lenz et al. 2016). However, in some cases, the concentration range used spans from environmentally realistic levels up to orders of magnitude higher (Lusher 2015). An important problem is that the particles used in different tests span through a wide range of ranges and shapes. A rescaling method has been recently proposed to adjust data from sources using different types of MPs when determining species sensitivity distributions (Koelmans et al. 2020)

\section{Knowledge gaps and research needs}

Several comprehensive reviews have been published collecting the bulk of the information available and trying to perform hazard and risk assessments (Adam et al. 2019; Burns and Boxall 2018; Kögel et al. 2020). The main conclusion that may be derived is that no adverse effects have been observed at concentrations comparable to the upper range of the distribution of the levels that have been measured in natural environments. Usually, adverse effects under laboratory conditions have been observed at levels that are orders of magnitude higher than environmentally realistic levels. A comparison between a safe concentration, estimated on the basis of available data on adverse effects, and projection of the concentration of global marine microplastics in a "business as usual" scenario, indicates that by the end of this century, the concentration of floating MPs will reach a level about two orders of magnitude lower than a threshold of risk, while a potential risk level will be reached only by the concentration of MPs that wash ashore in the marine environment (Everaert et al. 2018). Based on the available information, it may be concluded that the adverse effects of MPs do not represent a priority for further research, although some specific issues may be further investigated. For example, some details on the types of effects and modes of action remain to be clarified. Besides, the environmental relevance of the plastic material is rarely considered for impact assessment studies. More information is needed on the different test materials representing plastics from real consumer products and on their environmental behaviour when exposed to ageing conditions similar to natural environments.

\subsection{Translocation and transfer to the food web}

\section{State of the art}

The uptake of chemicals by living organisms is a process by which a contaminant is stored in the tissues to a level higher than the surrounding environment (Gobas and Morrison 2000). These processes may describe uptake patterns: (i) Bioconcentration is the accumulation of a chemical in the tissues of an organism because of direct exposure to the surrounding medium (e.g., water). The bioconcentration factor is the ratio of a contaminant concentration in biota to its concentration in the surrounding medium once equilibrium is reached. (ii) Bioaccumulation is the accumulation of chemicals in the tissue of organisms through any route, including respiration, food ingestion, or direct contact. (iii) Biomagnification is the increase of internal chemical concentration from lower to higher levels of the food chain, which depends not only on the physico-chemical properties of the chemical but on the trophic relations (Solomon et al. 2013). These processes may not occur with insoluble particulate materials, such as MPs, that cannot cross cellular membranes and enter the cells by passive diffusion regulated by partitioning mechanisms, as soluble chemicals do (Devito 2000; Schultz 1976). Therefore, they cannot accumulate in tissues unless other types of active processes, such as endocytosis-related mechanisms occur (Felix et al. 2017). The cellular uptake process of insoluble particulates is completely different from the passive diffusion process of 
bioaccumulative chemical compounds, and the assessment of their potential to bioaccumulate may require the development of new test systems, models, and mechanistic understanding (ECETOC 2019; Handy et al. 2018; Petersen et al. 2019; Roch et al. 2020).

The ingestion of MPs by aquatic and terrestrial animals has been widely documented in the literature (Wesch et al. 2016). According to Gouin, a huge number of individual organisms (about 87000) behaving to more than 800 different species have been analysed and MPs have been found in the gastrointestinal tract (GIT) of more than $20 \%$ of them, with an average of 4 MP items per individual (Gouin 2020). However, the presence of MPs in the GIT does not mean that a bioaccumulation process is occurring and does not necessarily represent a transfer to the food web comparable to biomagnification processes occurring with bioaccumulative chemicals. This consideration refers to MPs of medium-large size, i.e.: those that are easily detected and analysed. For small-size MPs, smaller than some tens of microns, and particularly for NPs, smaller than $1 \mu \mathrm{m}$, the problem is much more complex. Indeed, these particles cannot be detected, measured, and counted with the conventional analytical procedures usually applied to detect MPs. Due to technical limitations, the concentrations of NPs in the environment are currently unknown (GESAMP 2020). To date, there are no examples in the literature demonstrating the ingestion of NPs by free-living organisms, though some laboratory studies have attempted to investigate ingestion of NPs using labelled particles and environmentally unrealistic exposure levels (Skjolding et al. 2017).

\section{Knowledge gaps and research needs}

The capability of M/NPs to cross cell membranes and enter tissues is highly controversial. Large size MPs cannot, and the problem is limited to very small MPs and NPs. However, we lack information to determine to what extent small MPs and NPs may cross cell membranes. The potential for translocation of small size MPs and NPs from GIT to internal tissues, at least at very high levels, has been demonstrated (Triebskorn et al. 2019). Most of these results have been obtained using fluorescence- labelled NPs (Fig. 4). However, the reliability of results based on fluorescence-labelled MP-NPs is highly controversial, as it has been recently demonstrated that these results may be biased by experimental artefacts due to lipid accumulation of the leached fraction of hydrophobic fluorescent dye (Schür et al. 2019). An additional cause for concern is represented by a general lack of reproducibility of studies on the translocation of M/NPs into living organisms (Burns and Boxall 2018). It is also important to note that nano-sized plastics exhibit strong sorption affinities for toxic compounds (Mattsson et al. 2015). Therefore, their role as vector of fluorescent dies and other pollutants could be higher for NPs than for MPs.

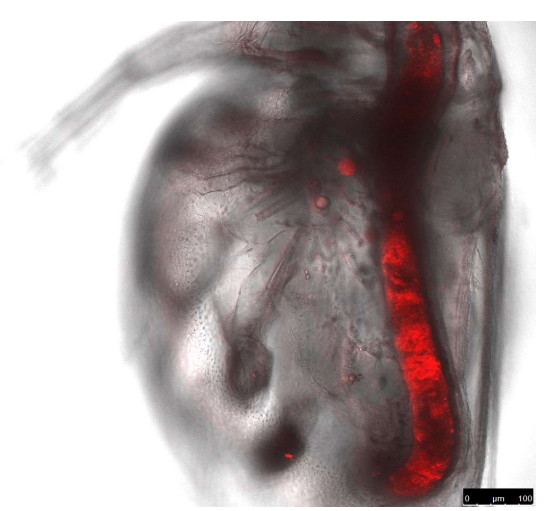

Figure 4. Rhodamine B labelled NPs in the gastrointestinal trait of Daphnia magna. Daphnia was exposed for 24 hours to PE NPs (about $100 \mathrm{~nm}$ ) at a concentration of $10 \mathrm{mg} / \mathrm{mL}$, corresponding to about $1.7 \times 10^{10} \mathrm{NP} / \mathrm{mL}$. The experiment was performed at IMDEA Water (Madrid Institute for Advanced Studies on Water, Spain). 
It is reasonable to suppose that there exists a size threshold below which particles can cross cell membranes and may be transferred into body tissues through passive diffusion mechanisms. Above this threshold, insoluble particles would enter cells only by endocytosis-related mechanisms or membrane disruption. Previous research performed with engineered nanoparticles showed that particle size is a key factor influencing passive permeation, and only particles below $10-50 \mathrm{~nm}$ tend to penetrate. Moreover, this is a complex process that tends to be regulated by several other factors such as hydrophobicity/hydrophilicity and surface modification of the particle, as well as environmental factors ( $\mathrm{pH}$, osmotic pressure, ionic strength; (Nakamura and Watano 2018). As for plastic particles, the first two are not expected to have a large influence given the hydrophobicity and non-reactivity of the constituent polymers, but the environmental factors can probably contribute do different cell permeation rates. Besides, the shape of the particles may affect their uptake into the cells, so that the permeability of tubular or irregular NPs may be different from that of rather globular particles.

Given the above, the major research priorities on the issue of bioaccumulation, biomagnification and transfer in the food web of M/NPs are: (i) developing, improving and calibrating standardized methods to extract, isolate, and identify MPs in organisms, particularly focused on the measurements of small-sized MPs and NPs; (ii) development of methods, test procedures and modelling approaches to assess, measure and predict the possible occurrence of cellular uptake of M/NPs trough endocytosis-related mechanisms and permeation; and (iii) assessing the capability of NPs (several tens of nanometers or less) to cross cellular membranes and to enter cells and tissues trough passive, diffusion-based mechanisms and quantifying the actual dimensional threshold and factors that influence this process. Experiments should be made using NPs of different sizes labelled with procedures different than fluorescence. A possibility is to use metal-doped NPs, which can be detected by ICP-MS thanks to the metal incorporated (Mitrano et al. 2019). Another option is the use of ${ }^{14} \mathrm{C}$ labelled polymers, and recently latexes of PS nanoparticles with size as low as 20 $\mathrm{nm}$ have been prepared using radiolabelled styrene that can be used to study the in vivo uptake of NPs in simulated environmental conditions (Al-Sid-Cheikh et al. 2020; Al-Sid-Cheikh et al. 2018). However, metal and ${ }^{14} \mathrm{C}$ labelled NPs are valid only for specific polymers, difficult to prepare and/or very expensive. Additionally, there are very few data on the presence of inhaled MPs in lungs either in animals or humans. Only a few studies have addressed this issue showing the presence of polymeric fibres in human lung tissues of people exposed to airborne microplastics (Pauly et al. 1998; Vianello et al. 2019). This is an important research topic that should be addressed in future studies.

\subsection{Nanoplastics}

\section{State of the art}

NPs have already been mentioned in several sections above. The reasons for concern are clear. Just one ethylene-vinyl acetate commercial buoy $(14.8 \mathrm{~cm} \times 9.5 \mathrm{~cm}, 110 \mathrm{~g})$ may produce $>10^{20}$ fragments of $100 \mathrm{~nm}$ NPs (own calculation). However, they represent the major knowledge gap in the general topic of plastics in the environment. It is reasonable to hypothesize that NPs may represent a major concern for the environment and human health. Nevertheless, to date, the information required to support this hypothesis is insufficient. According to Koelmans et al. "Nanoplastics is probably the least known area of marine litter but potentially also the most hazardous" (Koelmans et al. 2015). Specifically, there is no adequate information to assess the exposure and effects of nanoplastics and, therefore, to characterise the risk for the environment and human health. 


\section{Knowledge gaps and research needs}

The first key issue is the problem of sources and origins of NPs. As for MPs, NPs may be emitted as primary (i.e. intentionally produced) or secondary (i.e. non-intentionally produced) particles. Primary nanometre-sized particles may be produced using known synthesis processes and may be used for several applications (Rao and Geckeler 2011; Stephens et al. 2013). Secondary NPs can be produced in specific processes like the thermal cutting of PS foam (Zhang et al. 2012). Another possible source is the fragmentation of MPs to smaller-sized particles eventually reaching the nanoscale (Andrady 2011). However, to date, no precise data exist on these processes and any quantitative estimate of the possible emissions of primary and secondary NPs is largely hypothetical (Koelmans et al. 2015; Lehner et al. 2019). It is reasonable to suppose that NPs may be present in large amounts in all environmental matrices, but this is speculative and must be supported by experimental data.

A key issue is the lack of suitable and reliable methods for sampling and analysing NPs. The problem was already highlighted for small sized MPs $($ e.g.: $<20 \mu \mathrm{m})$ in previous sections and it is even more complex for NPs. For the sampling in the water environment, suitable methods for filtering in field large volumes of water, up to the nano-level are not realistically applicable. Therefore, a possibility could be taking water samples and processing in the lab with suitable approaches (e.g. ultra-filtration). This cannot be accomplished with large volume samples as for those needed for MP sampling (typically some cubic meters). Smaller volumes may be enough if NP concentration would be higher than those of MPs. This is probable, but it is just a speculative hypothesis because even the order of magnitude of NP concentration in natural waters is unknown. Comparable and even higher problems may arise for sampling in other environmental matrices like soil, sediments, or biota. The methods for analysis and detection of NPs are still in an early stage of development. Currently, there are no routine methods available that permit detection of NPs in any environmental matrices, including biota and food (Lehner et al. 2019; Peng et al. 2020). As mentioned before, thermo-analytical methods coupled with mass spectrometry offer the possibility of detecting polymer particles with sizes outside current analytical possibilities. The detection limits are expected to reach the nanogram per litre range with minimum sample pre-treatment (Yakovenko et al. 2020). Recently, pyrolysis gas chromatography time of flight mass spectrometry (Py-GC-ToF) has been proposed for the detection of marker ions from the compounds generated in the pyrolysis of M/NPs (Sullivan et al. 2020).

In addition, several studies have demonstrated that nanoparticle toxicity is extremely complex, and that the biological activity of nanoparticles will depend on a variety of physicochemical properties such as particle size, shape, agglomeration state, crystal structure, chemical composition, surface area and surface properties (Hofmann-Amtenbrink et al. 2015). Moreover, the concept of toxicity itself is unclear for insoluble particulate materials. As stated above, toxicity is a reaction between a chemical substance and a chemical structure of a living organism. Unlike medium-to-large MPs, NPs have higher possibilities to cross cell membranes and to enter cells (Section 3.9). Small size increases reactivity and possible breakdown in monomers (Lehner et al. 2019). Therefore, the possibility for true toxic effects increases. Experimental tests on the adverse effects of NPs on the environment and human health have been performed using in vitro assays (Lehner et al. 2019) and in vivo tests, mainly on aquatic organisms (Kögel et al. 2020; Liu et al. 2020; Liu et al. 2021). However, the information available is scarce compared to that recovered for MPs. In general, adverse effects have been observed at relatively high concentrations, but the lack of information on environmentally realistic concentrations in natural ecosystems makes impossible any characterisation of risk. Moreover, the types of adverse effects possible and the modes of action are largely unknown. 
The main knowledge gaps and needs for research on NPs may be summarized as follows: (i) better defining and quantitatively estimating emission sources; (ii) developing suitable sampling procedures in different environmental media; (iii) developing suitable and reliable analytical methods to quantify their environmental occurrence; (iv) assessing their capability to cross cell membranes and bioaccumulation potential; (v) assessing the possible modes of action and quantifying their adverse effects; and (vi) characterising the risks for different environmental compartments and for and human health.

\section{Conclusions and recommendations}

In the last few years, a large amount of resources has been allocated to conduct research in the field of plastic pollution and its effects. This has contributed to some extent to improve our knowledge on the occurrence of large MPs in different environmental compartments and to perform preliminary hazard and risk assessments, which generally indicate low risks for living organisms. We have also learned that this new research area needs further technological developments and cannot always rely on the approaches traditionally implemented in the risk assessment of chemical contaminants (sampling and analytical methods, toxicological risk assessments, etc.). Moreover, the development of techniques and concepts urgently requires coordination and harmonisation among different researchers and stakeholders. In general, many researchers share the idea that the results obtained were less than expected in relation to the efforts devoted, and that there are difficulties in the implementation and comparison of available scientific results. In addition, it seems that the focus on some key aspects needed to produce a suitable risk assessment has been frequently missed. Through this paper we have proposed a list of scientific issues that require to be better defined, clarified, or studied to advance the field. These have been discussed trough the text and schematically listed in Table 3. We sincerely hope that the list of research needs helps to optimize the use of human and economic resources dedicated to improving the risk assessment of M/NPs, and that aids in the development of effective mitigation strategies to counteract these risks in the near future.

Table 3. Synthesis of the main knowledge gaps that need to be considered for future research in the field of M/NPs.

\begin{tabular}{|c|c|}
\hline Knowledge gap & Why it should be considered \\
\hline \multicolumn{2}{|l|}{ Definitions } \\
\hline $\mathrm{M} / \mathrm{NPs}$ shape is generally ignored & $\begin{array}{l}\text {-Shape determines the viscous force and transport in fluid } \\
\text { media } \\
\text {-Shape influences colloidal stability } \\
\text {-Shape can also influence uptake by living organisms }\end{array}$ \\
\hline $\begin{array}{l}\text { Current size cut-off is inadequate } \\
\text { to fibres }\end{array}$ & $\begin{array}{l}\text {-Filter cut-off and size definition based on largest dimension } \\
\text { do not match } \\
\text {-Fibre length do not account for aerodynamic or } \\
\text { hydrodynamic behaviour }\end{array}$ \\
\hline $\begin{array}{l}\text { Other anthropogenic fibres are } \\
\text { rarely considered }\end{array}$ & $\begin{array}{l}\text {-Non-plastic industrially processed fibres bear the same } \\
\text { additives and appear together with those made of synthetic } \\
\text { polymers }\end{array}$ \\
\hline \multicolumn{2}{|l|}{ Environmental sources } \\
\hline $\begin{array}{l}\text { The mechanisms of generation of } \\
\text { secondary M/NPs in freshwater } \\
\text { environments are poorly known }\end{array}$ & $\begin{array}{l}\text {-The understanding of physical, chemical and biological } \\
\text { mechanisms affecting M/NPs fate in inland environments is } \\
\text { needed }\end{array}$ \\
\hline
\end{tabular}




\begin{tabular}{|c|c|}
\hline $\begin{array}{l}\text { Wastewater treatment processes } \\
\text { need improvements to limit the } \\
\text { emission of M/NPs }\end{array}$ & $\begin{array}{l}\text {-Wastewater treatment process and regulations (including } \\
\text { sludge management) should be developed to avoid current } \\
\text { emission of M/NPs }\end{array}$ \\
\hline $\begin{array}{l}\text { It is unclear if secondary M/NPs } \\
\text { from food packaging may be a } \\
\text { risk for human health }\end{array}$ & $\begin{array}{l}\text {-Risk assessment of M/NPs ingestion via food transfer } \\
\text { cannot be performed with currently available data }\end{array}$ \\
\hline $\begin{array}{l}\text { Available data are insufficient for } \\
\text { modelling }\end{array}$ & $\begin{array}{l}\text {-More data are needed to feed models that can predict the } \\
\text { accumulation and fate of M/NPs }\end{array}$ \\
\hline \multicolumn{2}{|l|}{ Sampling procedures } \\
\hline $\begin{array}{l}\text { Standardisation of sampling } \\
\text { methods }\end{array}$ & $\begin{array}{l}\text {-Standardisation of sampling procedures is needed to allow } \\
\text { comparing data from monitoring campaigns. } \\
\text {-Shape, colour and cross-cutting data about zooplankton and } \\
\text { environmental conditions should be systematically reported }\end{array}$ \\
\hline $\begin{array}{l}\text { Scarcity of data for the lower size } \\
\text { M/NPs }\end{array}$ & $\begin{array}{l}\text {-Limited data are available for } \mathrm{M} / \mathrm{NPs} \text { below } 100 \mu \mathrm{m} \text {, and } \\
\text { primarily in the nanometre range, which is the size range } \\
\text { with risk to translocate to biological tissues }\end{array}$ \\
\hline $\begin{array}{l}\text { Limited attention to freshwater, } \\
\text { soil and air compartments }\end{array}$ & $\begin{array}{l}\text {-Additional monitoring efforts should be oriented to inland } \\
\text { ecosystems as most plastic litter is originated from land } \\
\text { sources. }\end{array}$ \\
\hline \multicolumn{2}{|l|}{ Analytical methods } \\
\hline Non-comparable metrics & $\begin{array}{l}\text {-Metrics is a critical need to include } \mathrm{M} / \mathrm{NPs} \text { monitoring in } \\
\text { regulatory frameworks }\end{array}$ \\
\hline $\begin{array}{l}\text { Standardization of pretreatment } \\
\text { methods }\end{array}$ & $\begin{array}{l}\text {-Pretreatments aimed at removing organic matter or } \\
\text { separation from non-plastic particles affect the quality and } \\
\text { comparability of results from different sources }\end{array}$ \\
\hline $\begin{array}{l}\text { Scarcity of data for the smaller } \\
\text { size M/NPs }\end{array}$ & $\begin{array}{l}\text {-As for sampling methods, analytical methods for small size } \\
\text { MPs and or NPs are poorly reliable, inadequate or fully } \\
\text { lacking }\end{array}$ \\
\hline Poor statistics & $\begin{array}{l}\text {-The fraction of sample analysed by micro-FTIR or other } \\
\text { techniques should not be arbitrary, and accuracy must be } \\
\text { reported }\end{array}$ \\
\hline $\begin{array}{l}\text { Insufficient information about } \\
\text { cross-contamination/procedural } \\
\text { blanks and recovery rates }\end{array}$ & $\begin{array}{l}\text {-The results of procedural blanks should be reported, and } \\
\text { recovery rates should be evaluated }\end{array}$ \\
\hline \multicolumn{2}{|c|}{ Additives and other non-intentional substances } \\
\hline $\begin{array}{l}\text { Lack of information about } \\
\text { additives in marketed plastics }\end{array}$ & $\begin{array}{l}\text {-It is difficult to obtain information about substances } \\
\text { included in marketed materials }\end{array}$ \\
\hline $\begin{array}{l}\text { Limited information for } \\
\text { modelling or risk assessment }\end{array}$ & $\begin{array}{l}\text {-The impact of environmental variables on the leaching of } \\
\text { additives under realistic conditions is required for risk } \\
\text { assessment }\end{array}$ \\
\hline $\begin{array}{l}\text { Lack of information about by- } \\
\text { products or metabolites of } \\
\text { additives }\end{array}$ & $\begin{array}{l}\text {-The possible formation of toxic degradation products from } \\
\text { additives upon oxidation or photochemical processes } \\
\text { requires attention. }\end{array}$ \\
\hline \multicolumn{2}{|l|}{ Sorption of chemicals } \\
\hline $\begin{array}{l}\text { Different groups of living } \\
\text { organisms (e.g.: invertebrates) } \\
\text { and environmental compartments } \\
\text { (e.g.: sediments, soil) should be } \\
\text { considered }\end{array}$ & $\begin{array}{l}\text {-To date, major attention has been devoted to fish and the } \\
\text { aquatic compartment. The role of species with different } \\
\text { biological traits in the compartments that are the major sinks } \\
\text { of MPs and chemical contaminants is still unclear }\end{array}$ \\
\hline
\end{tabular}




\begin{tabular}{|c|c|}
\hline $\begin{array}{l}\text { The sorption of semipolar } \\
\text { pollutants in aged plastics } \\
\text { received less attention }\end{array}$ & $\begin{array}{l}\text {-The effect of ageing should also be considered because of } \\
\text { the different interaction of pollutants with hydrophilic } \\
\text { moieties, which may interact with polar and semipolar } \\
\text { compounds including antibiotics and other CEC }\end{array}$ \\
\hline \multicolumn{2}{|c|}{ Interaction with microorganisms } \\
\hline $\begin{array}{l}\text { The role of MPs as niche for } \\
\text { microorganisms is not well } \\
\text { understood. }\end{array}$ & $\begin{array}{l}\text {-MPs are a new microbial habitat that might already be } \\
\text { performing a role at the ecological level }\end{array}$ \\
\hline $\begin{array}{l}\text { MPs may contribute to disperse } \\
\text { microorganisms even to remote } \\
\text { areas }\end{array}$ & $\begin{array}{l}\text {-Potentially transported microbes include pathogens } \\
\text { (bacteria and viruses such as SARS-CoV-2) and ARB } \\
\text { possibly threatening human health and the environment }\end{array}$ \\
\hline $\begin{array}{l}\text { Colonized MPs area a source of } \\
\text { food for some aquatic organisms }\end{array}$ & $\begin{array}{l}\text {-Further research is needed to shed light on the potential } \\
\text { transfer of pathogens or ARB/ARG to these organisms and } \\
\text { to the aquatic trophic web }\end{array}$ \\
\hline $\begin{array}{l}\text { Microbes involved in polymer } \\
\text { degradation might be detected in } \\
\text { biofilms }\end{array}$ & $\begin{array}{l}\text {-Microbial assemblages on MPs may be a source of } \\
\text { organisms involved in polymer degradation }\end{array}$ \\
\hline \multicolumn{2}{|c|}{ Degradation and fate of microplastics } \\
\hline $\begin{array}{l}\text { Little is known about smaller size } \\
\text { MPs and no data exist about NPs }\end{array}$ & $\begin{array}{l}\text {-The generation of small fragments of M/NPs must be } \\
\text { modelled in order to perform a risk assessment }\end{array}$ \\
\hline $\begin{array}{l}\text { Aged M/NPs may be relatively } \\
\text { reactive }\end{array}$ & $\begin{array}{l}\text {-Plastic leachates can interact with certain chemicals with } \\
\text { consequences for human health and the ecosystems }\end{array}$ \\
\hline $\begin{array}{l}\text { Limited information on } \\
\text { biodegradable polymers }\end{array}$ & $\begin{array}{l}\text {-The degradation pattern and leaching of dissolved organic } \\
\text { carbon from biodegradable polymers are poorly known }\end{array}$ \\
\hline \multicolumn{2}{|c|}{ Translocation and transfer to the food web } \\
\hline $\begin{array}{l}\text { Limited data exist about the } \\
\text { capacity of M/NPs to cross cell } \\
\text { membranes }\end{array}$ & $\begin{array}{l}\text {-There is a need for developing standardized methods to } \\
\text { identify MPs in organisms, particularly small-sized MPs and } \\
\text { NPs including the mechanisms of cellular uptake }\end{array}$ \\
\hline $\begin{array}{l}\text { The importance of size for M/NPs } \\
\text { uptake needs to be determined }\end{array}$ & $\begin{array}{l}\text {-The influence of different parameters, notably size, on the } \\
\text { efficiency of internalization must be addressed in order to } \\
\text { prioritize risk }\end{array}$ \\
\hline \multicolumn{2}{|l|}{ Nanoplastics } \\
\hline $\begin{array}{l}\text { There is almost no information } \\
\text { about the presence, fate and } \\
\text { effects of NPs in the environment }\end{array}$ & $\begin{array}{l}\text {-No risk assessment is possible without reliable data about } \\
\text { NPs concentration in environmental compartments } \\
\text {-Reference materials are needed to further develop toxicity } \\
\text { tests }\end{array}$ \\
\hline
\end{tabular}

\section{Acknowledgements}

The authors wish to thank the support provided by the Spanish Ministry of Science through the Thematic Network of Micro- and Nanoplastics in the Environment (RED2018-102345-T, EnviroPlaNet). Andreu Rico is supported by a postdoctoral grant provided by the Spanish Ministry of Science, Innovation and Universities (IJCI-2017-33465).

\section{References}

Abbasi S, Keshavarzi B, Moore F, Turner A, Kelly FJ, Dominguez AO, Jaafarzadeh N (2019) Distribution and potential health impacts of microplastics and microrubbers in air and street dusts from Asaluyeh County, Iran. Environ. Pollut., 244:153-164 
Abeynayaka A, Kojima F, Miwa Y, Ito N, Nihei Y, Fukunaga Y, Yashima Y, Itsubo N (2020) Rapid sampling of suspended and floating microplastics in challenging riverine and coastal water environments in Japan. Water, 12:1903

Adam V, Yang T, Nowack B (2019) Toward an ecotoxicological risk assessment of microplastics: Comparison of available hazard and exposure data in freshwaters. Environ. Toxicol. Chem., 38:436-447

Al-Sid-Cheikh M, Rowland SJ, Kaegi R, Henry TB, Cormier M-A, Thompson RC (2020) Synthesis of ${ }^{14} \mathrm{C}$-labelled polystyrene nanoplastics for environmental studies. Commun. Mater., 1:97

Al-Sid-Cheikh M, Rowland SJ, Stevenson K, Rouleau C, Henry TB, Thompson RC (2018) Uptake, whole-body distribution, and depuration of nanoplastics by the scallop Pecten maximus at environmentally realistic concentrations. Environ. Sci. Technol., 52:14480-14486

Aliabad MK, Nassiri M, Kor K (2019) Microplastics in the surface seawaters of Chabahar Bay, Gulf of Oman (Makran Coasts). Mar. Pollut. Bull., 143:125-133

Amamiya K, Saido K, Chung S-Y, Hiaki T, Lee DS, Kwon BG (2019) Evidence of transport of styrene oligomers originated from polystyrene plastic to oceans by runoff. Sci. Total Environ., 667:57-63

Amaral-Zettler LA, Zettler ER, Mincer TJ (2020) Ecology of the plastisphere. Nat. Rev. Microbiol., 18:139-151

Amaral-Zettler LA, Zettler ER, Slikas B, Boyd GD, Melvin DW, Morrall CE, Proskurowski G, Mincer TJ (2015) The biogeography of the plastisphere: implications for policy. Front. Ecol. Environ., 13:541-546

Ambrogi V, Carfagna C, Cerruti P, Marturano V (2017) Additives in Polymers. In: Jasso-Gastinel CF, Kenny JM (eds) Modification of Polymer Properties. William Andrew Publishing, pp 87-108.

Andrade J, Fernández-González V, López-Mahía P, Muniategui S (2019) A low-cost system to simulate environmental microplastic weathering. Mar. Pollut. Bull., 149:110663

Andrade JM, Ferreiro B, López-Mahía P, Muniategui-Lorenzo S (2020) Standardization of the minimum information for publication of infrared-related data when microplastics are characterized. Mar. Pollut. Bull., 154:111035

Andrady AL (2011) Microplastics in the marine environment. Mar. Pollut. Bull., 62:1596-1605

Andrady AL, Neal MA (2009) Applications and societal benefits of plasticsPhil. Trans. R. Soc. B3641977-1984. Philos. Trans. R. Soc. London, Ser. B, 364:1977-1984

Arvanitoyannis IS, Bosnea L (2004) Migration of substances from food packaging materials to foods. Crit. Rev. Food Sci. Nutr., 44:63-76

Auta HS, Emenike CU, Fauziah SH (2017) Distribution and importance of microplastics in the marine environment: A review of the sources, fate, effects, and potential solutions. Environ. Int., 102:165-176

Aytan U, Valente A, Senturk Y, Usta R, Esensoy Sahin FB, Mazlum RE, Agirbas E (2016) First evaluation of neustonic microplastics in Black Sea waters. Mar. Environ. Res., 119:22-30

Bakir A, O'Connor IA, Rowland SJ, Hendriks AJ, Thompson RC (2016) Relative importance of microplastics as a pathway for the transfer of hydrophobic organic chemicals to marine life. Environ. Pollut., 219:56-65

Bandow N, Will V, Wachtendorf V, Simon F-G (2017) Contaminant release from aged microplastic. Environ. Chem., 14:394-405

Barnes DKA, Galgani F, Thompson RC, Barlaz M (2009) Accumulation and fragmentation of plastic debris in global environments. Philos. Trans. R. Soc. London, Ser. B, 364:1985-1998

Bayo J, Olmos S, López-Castellanos J (2020) Microplastics in an urban wastewater treatment plant: The influence of physicochemical parameters and environmental factors. Chemosphere, 238:124593

Baztan J, Bergmann M, Booth A, Broglio E, Carrasco A, Chouinard O, Clüsener-Godt M, Cordier M, Cozar A, Devrieses L, Enevoldsen H, Ernsteins R, Ferreira-da-Costa M, Fossi MC, Gago 
J, Galgani F, Garrabou J, Gerdts G, Gomez M, Gómez-Parra A, Gutow L, Herrera A, Herring C, Huck T, Huvet A, Ivar do Sul JA, Jorgensen B, Krzan A, Lagarde F, Liria A, Lusher A, Miguelez A, Packard T, Pahl S, Paul-Pont I, Peeters D, Robbens J, RuizFernández AC, Runge J, Sánchez-Arcilla A, Soudant P, Surette C, Thompson RC, Valdés L, Vanderlinden JP, Wallace N (2017) Breaking Down the Plastic Age. In: Baztan J, Jorgensen B, Pahl S, Thompson RC, Vanderlinden J-P (eds) Fate and Impact of Microplastics in Marine Ecosystems. Elsevier, pp 177-181.

Beaumont NJ, Aanesen M, Austen MC, Börger T, Clark JR, Cole M, Hooper T, Lindeque PK, Pascoe C, Wyles KJ (2019) Global ecological, social and economic impacts of marine plastic. Mar. Pollut. Bull., 142:189-195

Beer S, Garm A, Huwer B, Dierking J, Nielsen TG (2018) No increase in marine microplastic concentration over the last three decades - A case study from the Baltic Sea. Sci. Total Environ., 621:1272-1279

Beiras R, Muniategui-Lorenzo S, Rodil R, Tato T, Montes R, López-Ibáñez S, Concha-Graña E, Campoy-López P, Salgueiro-González N, Quintana JB (2019) Polyethylene microplastics do not increase bioaccumulation or toxicity of nonylphenol and 4-MBC to marine zooplankton. Sci. Total Environ., 692:1-9

Bejgarn S, MacLeod M, Bogdal C, Breitholtz M (2015) Toxicity of leachate from weathering plastics: An exploratory screening study with Nitocra spinipes. Chemosphere, 132:114-119

Bergami E, Bocci E, Vannuccini ML, Monopoli M, Salvati A, Dawson KA, Corsi I (2016) Nanosized polystyrene affects feeding, behavior and physiology of brine shrimp Artemia franciscana larvae. Ecotox. Environ. Saf., 123:18-25

Bergmann M, Mützel S, Primpke S, Tekman MB, Trachsel J, Gerdts G (2019) White and wonderful? Microplastics prevail in snow from the Alps to the Arctic. Sci. Adv., 5:eaax1157

Bergmann M, Wirzberger V, Krumpen T, Lorenz C, Primpke S, Tekman MB, Gerdts G (2017) High quantities of microplastic in Arctic deep-sea sediments from the HAUSGARTEN observatory. Environ. Sci. Technol., 51:11000-11010

Besseling E, Foekema EM, van den Heuvel-Greve MJ, Koelmans AA (2017) The effect of microplastic on the uptake of chemicals by the lugworm Arenicola marina (L.) under environmentally relevant exposure conditions. Environ. Sci. Technol., 51:8795-8804

Bhunia K, Sablani SS, Tang J, Rasco B (2013) Migration of chemical compounds from packaging polymers during microwave, conventional heat treatment, and storage. Compr. Rev. Food Sci. Food Saf., 12:523-545

Blázquez-Blázquez E, Cerrada ML, Benavente R, Pérez E (2020) Identification of additives in polypropylene and their degradation under solar exposure studied by gas dhromatographymass spectrometry. ACS Omega, 5:9055-9063

Brahney J, Hallerud M, Heim E, Hahnenberger M, Sukumaran S (2020) Plastic rain in protected areas of the United States. Science, 368:1257-1260

Bretas Alvim C, Mendoza-Roca JA, Bes-Piá A (2020) Wastewater treatment plant as microplastics release source - Quantification and identification techniques. J. Environ. Manage., 255:109739

Browne MA, Crump P, Niven SJ, Teuten E, Tonkin A, Galloway T, Thompson R (2011) Accumulation of microplastic on shorelines woldwide: Sources and sinks. Environ. Sci. Technol., 45:9175-9179

Brunner I, Fischer M, Rüthi J, Stierli B, Frey B (2018) Ability of fungi isolated from plastic debris floating in the shoreline of a lake to degrade plastics. PLoS One, 13:e0202047

Bryant JA, Clemente TM, Viviani DA, Fong AA, Thomas KA, Kemp P, Karl DM, White AE, DeLong EF (2016) Diversity and activity of communities inhabiting plastic debris in the North Pacific gyre. mSystems, 1:e00024-00016

Bullard JE, Ockelford A, O'Brien P, McKenna Neuman C (2021) Preferential transport of microplastics by wind. Atmos. Environ., 245:118038 
Burns EE, Boxall ABA (2018) Microplastics in the aquatic environment: Evidence for or against adverse impacts and major knowledge gaps. Environ. Toxicol. Chem., 37:2776-2796

Cai M, He H, Liu M, Li S, Tang G, Wang W, Huang P, Wei G, Lin Y, Chen B, Hu J, Cen Z (2018) Lost but can't be neglected: Huge quantities of small microplastics hide in the South China Sea. Sci. Total Environ., 633:1206-1216

Camacho M, Herrera A, Gómez M, Acosta-Dacal A, Martínez I, Henríquez-Hernández LA, Luzardo OP (2019) Organic pollutants in marine plastic debris from Canary Islands beaches. Sci. Total Environ., 662:22-31

Campanale C, Savino I, Pojar I, Massarelli C, Uricchio VF (2020) A practical overview of methodologies for sampling and analysis of microplastics in riverine environments. Sustainability, 12

Carr SA, Liu J, Tesoro AG (2016) Transport and fate of microplastic particles in wastewater treatment plants. Water Res., 91:174-182

Chae Y, An Y-J (2018) Current research trends on plastic pollution and ecological impacts on the soil ecosystem: A review. Environ. Pollut., 240:387-395

Chamas A, Moon H, Zheng J, Qiu Y, Tabassum T, Jang JH, Abu-Omar M, Scott SL, Suh S (2020) Degradation rates of plastics in the environment. ACS Sustainable Chem. Eng., 8:3494-3511

Chavarria-Miró G, Anfruns-Estrada E, Guix S, Paraira M, Galofré B, Sáanchez G, Pintó R, Bosch A (2020) Sentinel surveillance of SARS-CoV-2 in wastewater anticipates the occurrence of COVID-19 cases. MedRxiv: 2020.2006.2013.20129627

Cheung PK, Fok L, Hung PL, Cheung LTO (2018) Spatio-temporal comparison of neustonic microplastic density in Hong Kong waters under the influence of the Pearl River Estuary. Sci. Total Environ., 628-629:731-739

Cincinelli A, Scopetani C, Chelazzi D, Lombardini E, Martellini T, Katsoyiannis A, Fossi MC, Corsolini S (2017) Microplastic in the surface waters of the Ross Sea (Antarctica): Occurrence, distribution and characterization by FTIR. Chemosphere, 175:391-400

Cole M, Lindeque P, Fileman E, Halsband C, Galloway TS (2015) The impact of polystyrene microplastics on feeding, function and fecundity in the marine copepod Calanus helgolandicus. Environ. Sci. Technol., 49:1130-1137

Cole M, Lindeque P, Halsband C, Galloway TS (2011) Microplastics as contaminants in the marine environment: A review. Mar. Pollut. Bull., 62:2588-2597

Collignon A, Hecq J-H, Galgani F, Collard F, Goffart A (2014) Annual variation in neustonic micro- and meso-plastic particles and zooplankton in the Bay of Calvi (MediterraneanCorsica). Mar. Pollut. Bull., 79:293-298

Collignon A, Hecq J-H, Glagani F, Voisin P, Collard F, Goffart A (2012) Neustonic microplastic and zooplankton in the North Western Mediterranean Sea. Mar. Pollut. Bull., 64:861-864

Cox KD, Covernton GA, Davies HL, Dower JF, Juanes F, Dudas SE (2019) Human Consumption of Microplastics. Environ. Sci. Technol., 53:7068-7074

Cózar A, Martí E, Duarte CM, García-de-Lomas J, van Sebille E, Ballatore TJ, Eguíluz VM, González-Gordillo JI, Pedrotti ML, Echevarría F, Troublè R, Irigoien X (2017) The Arctic Ocean as a dead end for floating plastics in the North Atlantic branch of the Thermohaline Circulation. Sci. Adv., 3:e1600582

Cózar A, Sanz-Martín M, Martí E, González-Gordillo JI, Ubeda B, Gálvez JÁ, Irigoien X, Duarte CM (2015) Plastic accumulation in the Mediterranean Sea. PLoS One, 10:e0121762

Crawford CB, Quinn B (2017) 6 - The interactions of microplastics and chemical pollutants. In: Crawford CB, Quinn B (eds) Microplastic Pollutants. Elsevier, pp 131-157.

Darbra RM, Dan JRG, Casal J, Àgueda A, Capri E, Fait G, Schuhmacher M, Nadal M, Rovira J, Grundmann V, Barceló D, Ginebreda A, Guillén D (2012) Additives in the Textile Industry. In: Bilitewski B, Darbra RM, Barceló D (eds) Global Risk-Based Management of Chemical Additives I: Production, Usage and Environmental Occurrence. Springer Berlin Heidelberg, Berlin, Heidelberg, pp 83-107. 
de Lucia GA, Caliani I, Marra S, Camedda A, Coppa S, Alcaro L, Campani T, Giannetti M, Coppola D, Cicero AM, Panti C, Baini M, Guerranti C, Marsili L, Massaro G, Fossi MC, Matiddi M (2014) Amount and distribution of neustonic micro-plastic off the western Sardinian coast (Central-Western Mediterranean Sea). Mar. Environ. Res., 100:10-16 de Sá LC, Luís LG, Guilhermino L (2015) Effects of microplastics on juveniles of the common goby (Pomatoschistus microps): Confusion with prey, reduction of the predatory performance and efficiency, and possible influence of developmental conditions. Environ. Pollut., 196:359-362

de Sá LC, Oliveira M, Ribeiro F, Rocha TL, Futter MN (2018) Studies of the effects of microplastics on aquatic organisms: What do we know and where should we focus our efforts in the future? Sci. Total Environ., 645:1029-1039

De Tender C, Devriese LI, Haegeman A, Maes S, Vangeyte J, Cattrijsse A, Dawyndt P, Ruttink T (2017) Temporal dynamics of bacterial and fungal colonization on plastic debris in the North Sea. Environ. Sci. Technol., 51:7350-7360

Devito SC (2000) Absorption through cellular membranes. Handbook of property estimation methods for chemicals. In: Boethling RS, Mackay D (eds) Handbook of Property Estimation Methods for Chemicals: Environmental and Health Sciences. CRC Press-Lewis, Boca Raton, pp 261-278.

Di Mauro R, Kupchik MJ, Benfield MC (2017) Abundant plankton-sized microplastic particles in shelf waters of the northern Gulf of Mexico. Environ. Pollut., 230:798-809

Dominguez G, McLeod AS, Gainsforth Z, Kelly P, Bechtel HA, Keilmann F, Westphal A, Thiemens M, Basov DN (2014) Nanoscale infrared spectroscopy as a non-destructive probe of extraterrestrial samples. Nat. Commun., 5:5445

Doyle MJ, Watson W, Bowlin NM, Sheavly SB (2011) Plastic particles in coastal pelagic ecosystems of the Northeast Pacific ocean. Mar. Environ. Res., 71:41-52

Dris R, Gasperi J, Saad M, Mirande C, Tassin B (2016) Synthetic fibers in atmospheric fallout: A source of microplastics in the environment? Mar. Pollut. Bull., 104:290-293

Dussud C, Hudec C, George M, Fabre P, Higgs P, Bruzaud S, Delort A-M, Eyheraguibel B, Meistertzheim A-L, Jacquin J, Cheng J, Callac N, Odobel C, Rabouille S, Ghiglione J-F (2018) Colonization of non-biodegradable and biodegradable plastics by marine microorganisms. Front. Microbiol., 9:1571-1571

Dyachenko A, Mitchell J, Arsem N (2017) Extraction and identification of microplastic particles from secondary wastewater treatment plant (WWTP) effluent. Anal. Methods, 9:1412-1418

ECETOC (2019) An evaluation of the challenges and limitations associated with aquatic toxicity and bioaccumulation studies for sparingly soluble and manufactured particulate substances. An evaluation of the challenges and limitations associated with aquatic toxicity and bioaccumulation studies for sparingly soluble and manufactured particulate substances, Technical Report No 132. ECETOC, Brussels.

ECHA (2019) Annex XV Restriction Report. Proposal for a restriction of intentionally added microplastics. Version 1.1. 20th/March/2019. Helsinki.

Edo C, González-Pleiter M, Leganés F, Fernández-Piñas F, Rosal R (2020) Fate of microplastics in wastewater treatment plants and their environmental dispersion with effluent and sludge. Environ. Pollut., 259:113837

Eerkes-Medrano D, Thompson RC, Aldridge DC (2015) Microplastics in freshwater systems: A review of the emerging threats, identification of knowledge gaps and prioritisation of research needs. Water Res., 75:63-82

Enders K, Lenz R, Stedmon CA, Nielsen TG (2015) Abundance, size and polymer composition of marine microplastics $\geq 10 \mu \mathrm{m}$ in the Atlantic Ocean and their modelled vertical distribution. Mar. Pollut. Bull., 100:70-81 
Eriksen M, Lebreton LCM, Carson HS, Thiel M, Moore CJ, Borerro JC, Galgani F, Ryan PG, Reisser J (2014) Plastic pollution in the world's oceans: More than 5 trillion plastic pieces weighing over 250,000 tons afloat at sea. PLoS One, 9:e111913

Eriksen M, Maximenko N, Thiel M, Cummins A, Lattin G, Wilson S, Hafner J, Zellers A, Rifman S (2013) Plastic pollution in the South Pacific subtropical gyre. Mar. Pollut. Bull., 68:71-76

Everaert G, Van Cauwenberghe L, De Rijcke M, Koelmans AA, Mees J, Vandegehuchte M, Janssen CR (2018) Risk assessment of microplastics in the ocean: Modelling approach and first conclusions. Environ. Pollut., 242:1930-1938

Fadare OO, Wan B, Guo L-H, Zhao L (2020) Microplastics from consumer plastic food containers: Are we consuming it? Chemosphere, 253:126787

Faure F, Demars C, Wieser O, Kunz M, de Alencastro LF (2015) Plastic pollution in Swiss surface waters: nature and concentrations, interaction with pollutants. Environ. Chem., 12:582-591

Felix LC, Ortega VA, Goss GG (2017) Cellular uptake and intracellular localization of poly (acrylic acid) nanoparticles in a rainbow trout (Oncorhynchus mykiss) gill epithelial cell line, RTgillW1. Aquat. Toxicol., 192:58-68

Fendall LS, Sewell MA (2009) Contributing to marine pollution by washing your face: Microplastics in facial cleansers. Mar. Pollut. Bull., 58:1225-1228

Fernández-González V, Andrade-Garda JM, López-Mahía P, Muniategui-Lorenzo S (2021) Impact of weathering on the chemical identification of microplastics from usual packaging polymers in the marine environment. Anal. Chim. Acta, 1142:179-188

Figueiredo GM, Vianna TMP (2018) Suspended microplastics in a highly polluted bay: Abundance, size, and availability for mesozooplankton. Mar. Pollut. Bull., 135:256-265

Fischer M, Scholz-Böttcher BM (2017) Simultaneous trace identification and quantification of common types of microplastics in environmental samples by pyrolysis-gas chromatography-mass spectrometry. Environ. Sci. Technol., 51:5052-5060

Flemming H-C, Neu TR, Wozniak DJ (2007) The EPS matrix: The "house of biofilm cells". J. Bacteriol., 189:7945-7947

Fossi MC, Baini M, Panti C, Galli M, Jiménez B, Muñoz-Arnanz J, Marsili L, Finoia MG, Ramírez-Macías D (2017) Are whale sharks exposed to persistent organic pollutants and plastic pollution in the Gulf of California (Mexico)? First ecotoxicological investigation using skin biopsies. Comp. Biochem. Physiol. C: Toxicol. Pharmacol., 199:48-58

Frère L, Paul-Pont I, Rinnert E, Petton S, Jaffré J, Bihannic I, Soudant P, Lambert C, Huvet A (2017) Influence of environmental and anthropogenic factors on the composition, concentration and spatial distribution of microplastics: A case study of the Bay of Brest (Brittany, France). Environ. Pollut., 225:211-222

Frias JPGL, Nash R (2019) Microplastics: Finding a consensus on the definition. Mar. Pollut. Bull., 138:145-147

Frias JPGL, Otero V, Sobral P (2014) Evidence of microplastics in samples of zooplankton from Portuguese coastal waters. Mar. Environ. Res., 95:89-95

Fries E, Dekiff JH, Willmeyer J, Nuelle M-T, Ebert M, Remy D (2013) Identification of polymer types and additives in marine microplastic particles using pyrolysis-GC/MS and scanning electron microscopy. Environ. Sci. Processes Impacts, 15:1949-1956

Fu W, Min J, Jiang W, Li Y, Zhang W (2020) Separation, characterization and identification of microplastics and nanoplastics in the environment. Sci. Total Environ., 721:137561

Gago J, Carretero O, Filgueiras AV, Viñas L (2018) Synthetic microfibers in the marine environment: A review on their occurrence in seawater and sediments. Mar. Pollut. Bull., 127:365-376

Gago J, Henry M, Galgani F (2015) First observation on neustonic plastics in waters off NW Spain (spring 2013 and 2014). Mar. Environ. Res., 111:27-33 
GESAMP (2015) Sources, fate and effects of microplastic in the marine environment: A global assessment. Kershaw PJ (ed) Sources, fate and effects of microplastic in the marine environment: A global assessment, Rep. Stud. GESAMP No. 93. p 220.

GESAMP (2016) Sources, fate and effects of microplastic in the marine environment: Part two of a global assessment. Kershaw PJ, Rochman CM (eds) Sources, fate and effects of microplastic in the marine environment: Part two of a global assessment, Rep. Stud. GESAMP No. 93. p 220.

GESAMP (2019) Guidelines for the monitoring and assessment of plastic litter in the ocean. Kershaw PJ, Turra A, Galgani F (eds) Guidelines for the monitoring and assessment of plastic litter in the ocean, Rep. Stud. GESAMP No. 99. p 130.

GESAMP (2020) Proceedings of the GESAMP International Workshop on assessing the risks associated with plastics and microplastics in the marine environment. Kershaw PJ, Carney B, Villarrubia-Gómez P, Koelmans AA, Gouin T (eds) Proceedings of the GESAMP International Workshop on assessing the risks associated with plastics and microplastics in the marine environment. Reports to GESAMP No. 103. p 68.

Gewert B, Ogonowski M, Barth A, MacLeod M (2017) Abundance and composition of near surface microplastics and plastic debris in the Stockholm Archipelago, Baltic Sea. Mar. Pollut. Bull., 120:292-302

Gewert B, Plassmann MM, MacLeod M (2015) Pathways for degradation of plastic polymers floating in the marine environment. Environ. Sci. Processes Impacts, 17:1513-1521

Gigault J, Halle At, Baudrimont M, Pascal P-Y, Gauffre F, Phi T-L, El Hadri H, Grassl B, Reynaud S (2018) Current opinion: What is a nanoplastic? Environ. Pollut., 235:1030-1034

Gilfillan LR, Ohman MD, Doyle MJ, Watson W (2009) Occurrence of plastic micro-debris in the Southern California Current System. Reports CCOFI (ed) Occurrence of plastic microdebris in the Southern California Current System. 50. pp 123-133.

Gobas FAFP, Morrison H, A. (2000) Bioconcentration and biomagnification in the aquatic environment. In: Boethling RS, Mackay D (eds) Handbook of Property Estimation Methods for Chemicals: Environmental and Health Sciences. CRC Press-Lewis, Boca Rtaon, pp 189231.

Gong J, Xie P (2020) Research progress in sources, analytical methods, eco-environmental effects, and control measures of microplastics. Chemosphere, 254:126790

González-Pleiter M, Edo C, Aguilera Á, Viúdez-Moreiras D, Pulido-Reyes G, González-Toril E, Osuna S, de Diego-Castilla G, Leganés F, Fernández-Piñas F, Rosal R (2021) Occurrence and transport of microplastics sampled within and above the planetary boundary layer. Sci. Total Environ., 761:143213

González-Pleiter M, Tamayo-Belda M, Pulido-Reyes G, Amariei G, Leganés F, Rosal R, Fernández-Piñas F (2019) Secondary nanoplastics released from a biodegradable microplastic severely impact freshwater environments. Environ. Sci. Nano, 6:1382-1392

González-Pleiter M, Velázquez D, Edo C, Carretero O, Gago J, Barón-Sola Á, Hernández LE, Yousef I, Quesada A, Leganés F, Rosal R, Fernández-Piñas F (2020) Fibers spreading worldwide: Microplastics and other anthropogenic litter in an Arctic freshwater lake. Sci. Total Environ., 722:137904

Gouin T (2020) Towards improved understanding of the ingestion and trophic transfer of microplastic particles - Critical review and implications for future research. Environ. Toxicol. Chem., 39:1119-1137

Gouin T, Roche N, Lohmann R, Hodges G (2011) A thermodynamic approach for assessing the environmental exposure of chemicals absorbed to microplastic. Environ. Sci. Technol., 45:1466-1472

Groh KJ, Backhaus T, Carney-Almroth B, Geueke B, Inostroza PA, Lennquist A, Leslie HA, Maffini M, Slunge D, Trasande L, Warhurst AM, Muncke J (2019) Overview of known 
plastic packaging-associated chemicals and their hazards. Sci. Total Environ., 651:32533268

Hahladakis JN, Velis CA, Weber R, Iacovidou E, Purnell P (2018) An overview of chemical additives present in plastics: Migration, release, fate and environmental impact during their use, disposal and recycling. J. Hazard. Mater., 344:179-199

Handy RD, Ahtiainen J, Navas JM, Goss G, Bleeker EAJ, von der Kammer F (2018) Proposal for a tiered dietary bioaccumulation testing strategy for engineered nanomaterials using fish. Environ. Sci. Nano, 5:2030-2046

Harrison JP, Schratzberger M, Sapp M, Osborn AM (2014) Rapid bacterial colonization of lowdensity polyethylene microplastics in coastal sediment microcosms. BMC Microbiol., $14: 232$

Hartmann NB, Hüffer T, Thompson RC, Hassellöv M, Verschoor A, Daugaard AE, Rist S, Karlsson T, Brennholt N, Cole M, Herrling MP, Hess MC, Ivleva NP, Lusher AL, Wagner M (2019) Are we speaking the same language? Recommendations for a definition and categorization framework for plastic debris. Environ. Sci. Technol., 53:1039-1047

Hendriksen RS, Munk P, Njage P, van Bunnik B, McNally L, Lukjancenko O, Röder T, Nieuwenhuijse D, Pedersen SK, Kjeldgaard J, Kaas RS, Clausen PTLC, Vogt JK, Leekitcharoenphon P, van de Schans MGM, Zuidema T, de Roda Husman AM, Rasmussen S, Petersen B, Bego A, Rees C, Cassar S, Coventry K, Collignon P, Allerberger F, Rahube TO, Oliveira G, Ivanov I, Vuthy Y, Sopheak T, Yost CK, Ke C, Zheng H, Baisheng L, Jiao X, Donado-Godoy P, Coulibaly KJ, Jergović M, Hrenovic J, Karpíšková R, Villacis JE, Legesse M, Eguale T, Heikinheimo A, Malania L, Nitsche A, Brinkmann A, Saba CKS, Kocsis B, Solymosi N, Thorsteinsdottir TR, Hatha AM, Alebouyeh M, Morris D, Cormican M, O'Connor L, Moran-Gilad J, Alba P, Battisti A, Shakenova Z, Kiiyukia C, Ng'eno E, Raka L, Avsejenko J, Bērziņš A, Bartkevics V, Penny C, Rajandas H, Parimannan S, Haber MV, Pal P, Jeunen G-J, Gemmell N, Fashae K, Holmstad R, Hasan R, Shakoor S, Rojas MLZ, Wasyl D, Bosevska G, Kochubovski M, Radu C, Gassama A, Radosavljevic V, Wuertz S, Zuniga-Montanez R, Tay MYF, Gavačová D, Pastuchova K, Truska P, Trkov M, Esterhuyse K, Keddy K, Cerdà-Cuéllar M, Pathirage S, Norrgren L, Örn S, Larsson DGJ, Heijden TVd, Kumburu HH, Sanneh B, Bidjada P, Njanpop-Lafourcade B-M, NikiemaPessinaba SC, Levent B, Meschke JS, Beck NK, Van CD, Phuc ND, Tran DMN, Kwenda G, Tabo D-a, Wester AL, Cuadros-Orellana S, Amid C, Cochrane G, Sicheritz-Ponten T, Schmitt H, Alvarez JRM, Aidara-Kane A, Pamp SJ, Lund O, Hald T, Woolhouse M, Koopmans MP, Vigre H, Petersen TN, Aarestrup FM, The Global Sewage Surveillance project c (2019) Global monitoring of antimicrobial resistance based on metagenomics analyses of urban sewage. Nat. Commun., 10:1124

Henry B, Laitala K, Klepp IG (2019) Microfibres from apparel and home textiles: Prospects for including microplastics in environmental sustainability assessment. Sci. Total Environ., 652:483-494

Hermabessiere L, Dehaut A, Paul-Pont I, Lacroix C, Jezequel R, Soudant P, Duflos G (2017) Occurrence and effects of plastic additives on marine environments and organisms: A review. Chemosphere, 182:781-793

Hernandez LM, Xu EG, Larsson HCE, Tahara R, Maisuria VB, Tufenkji N (2019) Plastic teabags release billions of microparticles and nanoparticles into tea. Environ. Sci. Technol., 53:12300-12310

Herrera A, Raymond E, Martínez I, Álvarez S, Canning-Clode J, Gestoso I, Pham CK, Ríos N, Rodríguez Y, Gómez M (2020) First evaluation of neustonic microplastics in the Macaronesian region, NE Atlantic. Mar. Pollut. Bull., 153:110999

Hoellein T, Rojas M, Pink A, Gasior J, Kelly J (2014) Anthropogenic litter in urban freshwater ecosystems: Distribution and microbial interactions. PLoS One, 9:e98485 
Hofmann-Amtenbrink M, Grainger DW, Hofmann H (2015) Nanoparticles in medicine: Current challenges facing inorganic nanoparticle toxicity assessments and standardizations. Nanomed. Nanotechnol. Biol. Med., 11:1689-1694

Hoppe M, de Voogt P, Franz R (2016) Identification and quantification of oligomers as potential migrants in plastics food contact materials with a focus in polycondensates - A review. Trends Food Sci. Technol., 50:118-130

Hoppe M, Fornari R, de Voogt P, Franz R (2017) Migration of oligomers from PET: determination of diffusion coefficients and comparison of experimental versus modelled migration. Food Addit. Contam., Part A, 34:1251-1260

Isobe A, Uchida K, Tokai T, Iwasaki S (2015) East Asian seas: A hot spot of pelagic microplastics. Mar. Pollut. Bull., 101:618-623

Isobe A, Uchiyama-Matsumoto K, Uchida K, Tokai T (2017) Microplastics in the Southern Ocean. Mar. Pollut. Bull., 114:623-626

Ivar do Sul JA, Costa MF, Fillmann G (2014) Microplastics in the pelagic environment around oceanic islands of the Western Tropical Atlantic Ocean. Water Air Soil Pollut., 225:2004

Jacquin J, Cheng J, Odobel C, Pandin C, Conan P, Pujo-Pay M, Barbe V, Meistertzheim A-L, Ghiglione J-F (2019) Microbial ecotoxicology of marine plastic debris: A review on colonization and biodegradation by the "Plastisphere". Front. Microbiol., 10:865-865

Jahnke A, Mayer P, McLachlan MS (2012) Sensitive equilibrium sampling to study polychlorinated biphenyl disposition in Baltic Sea sediment. Environ. Sci. Technol., 46:10114-10122

Jaiswal S, Sharma B, Shukla P (2020) Integrated approaches in microbial degradation of plastics. Environ. Technol. Innovation, 17:100567

Julienne F, Delorme N, Lagarde F (2019) From macroplastics to microplastics: Role of water in the fragmentation of polyethylene. Chemosphere, 236:124409

Kalogerakis N, Karkanorachaki K, Kalogerakis GC, Triantafyllidi EI, Gotsis AD, Partsinevelos P, Fava F (2017) Microplastics generation: Onset of fragmentation of polyethylene films in marine environment mesocosms. Front. Mar. Sci., 4:84

Kang J-H, Kwon OY, Lee K-W, Song YK, Shim WJ (2015) Marine neustonic microplastics around the southeastern coast of Korea. Mar. Pollut. Bull., 96:304-312

Kanhai LDK, Officer R, Lyashevska O, Thompson RC, O'Connor I (2017) Microplastic abundance, distribution and composition along a latitudinal gradient in the Atlantic Ocean. Mar. Pollut. Bull., 115:307-314

Karlsson TM, Kärrman A, Rotander A, Hassellöv M (2020) Comparison between manta trawl and in situ pump filtration methods, and guidance for visual identification of microplastics in surface waters. Environ. Sci. Pollut. Res., 27:5559-5571

Kedzierski M, Lechat B, Sire O, Le Maguer G, Le Tilly V, Bruzaud S (2020) Microplastic contamination of packaged meat: Occurrence and associated risks. Food Pack. Shelf Life, 24:100489

Kedzierski M, Villain J, Falcou-Préfol M, Kerros ME, Henry M, Pedrotti ML, Bruzaud S (2019) Microplastics in Mediterranean Sea: A protocol to robustly assess contamination characteristics. PLoS One, 14:e0212088

Kettner MT, Rojas-Jimenez K, Oberbeckmann S, Labrenz M, Grossart H-P (2017) Microplastics alter composition of fungal communities in aquatic ecosystems. Environ. Microbiol., 19:4447-4459

Kim HJ, Lee S-H, Lee J-H, Jang SP (2015) Effect of particle shape on suspension stability and thermal conductivities of water-based bohemite alumina nanofluids. Energy, 90:1290-1297

Klein M, Fischer EK (2019) Microplastic abundance in atmospheric deposition within the Metropolitan area of Hamburg, Germany. Sci. Total Environ., 685:96-103

Klein S, Dimzon IK, Eubeler J, Knepper TP (2018) Analysis, occurrence, and degradation of microplastics in the aqueous environment. In: Wagner M, Lambert S (eds) Freshwater Microplastics. Emerging Environmental Contaminants? Springer, pp 51-67. 
Koelmans AA (2015) Modeling the role of microplastics in bioaccumulation of organic chemicals to marine aquatic organisms. A critical review. In: Bergmann M, Gutow L, Klages M (eds) Marine Anthropogenic Litter. Springer International Publishing, Cham, pp 309-324.

Koelmans AA, Bakir A, Burton GA, Janssen CR (2016) Microplastic as a Vector for Chemicals in the Aquatic Environment: Critical Review and Model-Supported Reinterpretation of Empirical Studies. Environ. Sci. Technol., 50:3315-3326

Koelmans AA, Besseling E, Foekema E, Kooi M, Mintenig S, Ossendorp BC, RedondoHasselerharm PE, Verschoor A, van Wezel AP, Scheffer M (2017a) Risks of plastic debris: Unravelling fact, opinion, perception, and belief. Environ. Sci. Technol., 51:11513-11519

Koelmans AA, Besseling E, Foekema EM (2014) Leaching of plastic additives to marine organisms. Environ. Pollut., 187:49-54

Koelmans AA, Besseling E, Shim WJ (2015) Nanoplastics in the aquatic environment. Critical review. In: Bergmann M, Gutow L, Klages M (eds) Marine Anthropogenic Litter. Springer International Publishing, Cham, pp 325-340.

Koelmans AA, Kooi M, Law KL, Van Sebille E (2017b) All is not lost: Deriving a top-down mass budget of plastic at sea. Environ. Res. Lett., 12:114028

Koelmans AA, Redondo-Hasselerharm PE, Mohamed Nor NH, Kooi M (2020) Solving the nonalignment of methods and approaches used in microplastic research to consistently characterize risk. Environ. Sci. Technol., 54:12307-12315

Kögel T, Bjorøy Ø, Toto B, Bienfait AM, Sanden M (2020) Micro- and nanoplastic toxicity on aquatic life: Determining factors. Sci. Total Environ., 709:136050

Kor K, Mehdinia A (2020) Neustonic microplastic pollution in the Persian Gulf. Mar. Pollut. Bull., 150:110665

Kroon FJ, Motti CE, Jensen LH, Berry KLE (2018) Classification of marine microdebris: A review and case study on fish from the Great Barrier Reef, Australia. Sci. Rep., 8:16422

Kuhn S, Bravo-Rebolledo E, van Franeker JA (2015) Deleterious effects of litter on marine life. In: Bergmann M, Gutow L, Klages M (eds) Marine Anthropogenic Litter. Springer International Publishing, pp 75-116.

Kukulka T, Proskurowski G, Morét-Ferguson S, Meyer DW, Law KL (2012) The effect of wind mixing on the vertical distribution of buoyant plastic debris. Geophys. Res. Lett., 39:7601

Laganà $\mathrm{P}$, Caruso G, Corsi I, Bergami E, Venuti V, Majolino D, La Ferla R, Azzaro M, Cappello S (2019) Do plastics serve as a possible vector for the spread of antibiotic resistance? First insights from bacteria associated to a polystyrene piece from King George Island (Antarctica). Int. J. Hyg. Environ. Health, 222:89-100

Lattin GL, Moore CJ, Zellers AF, Moore SL, Weisberg SB (2004) A comparison of neustonic plastic and zooplankton at different depths near the southern California shore. Mar. Pollut. Bull., 49:291-294

Law KL, Morét-Ferguson SE, Goodwin DS, Zettler ER, DeForce E, Kukulka T, Proskurowski G (2014) Distribution of surface plastic debris in the Eastern Pacific Ocean from an 11-year data set. Environ. Sci. Technol., 48:4732-4738

Lebreton L, Slat B, Ferrari F, Sainte-Rose B, Aitken J, Marthouse R, Hajbane S, Cunsolo S, Schwarz A, Levivier A, Noble K, Debeljak P, Maral H, Schoeneich-Argent R, Brambini R, Reisser J (2018) Evidence that the Great Pacific Garbage Patch is rapidly accumulating plastic. Sci. Rep., 8:4666-4666

Lee OO, Wang Y, Tian R, Zhang W, Shek CS, Bougouffa S, Al-Suwailem A, Batang ZB, Xu W, Wang GC, Zhang X, Lafi FF, Bajic VB, Qian P-Y (2014) In situ environment rather than substrate type dictates microbial community structure of biofilms in a cold seep system. Sci. Rep., 4:3587

Lee YK, Romera-Castillo C, Hong S, Hur J (2020) Characteristics of microplastic polymer-derived dissolved organic matter and its potential as a disinfection byproduct precursor. Water Res., 175:115678 
Lehner R, Weder C, Petri-Fink A, Rothen-Rutishauser B (2019) Emergence of nanoplastic in the environment and possible impact on human health. Environ. Sci. Technol., 53:1748-1765

Lenz R, Enders K, Nielsen TG (2016) Microplastic exposure studies should be environmentally realistic. PNAS, 113:E4121-E4122

León VM, García I, González E, Samper R, Fernández-González V, Muniategui-Lorenzo S (2018) Potential transfer of organic pollutants from littoral plastics debris to the marine environment. Environ. Pollut., 236:442-453

Leslie HA, Brandsma SH, van Velzen MJM, Vethaak AD (2017) Microplastics en route: Field measurements in the Dutch river delta and Amsterdam canals, wastewater treatment plants, North Sea sediments and biota. Environ. Int., 101:133-142

Li J, Liu H, Paul Chen J (2018) Microplastics in freshwater systems: A review on occurrence, environmental effects, and methods for microplastics detection. Water Res., 137:362-374

Li J, Song Y, Cai Y (2020) Focus topics on microplastics in soil: Analytical methods, occurrence, transport, and ecological risks. Environ. Pollut., 257:113570

Lima ARA, Costa MF, Barletta M (2014) Distribution patterns of microplastics within the plankton of a tropical estuary. Environ. Res., 132:146-155

Liu F, Olesen KB, Borregaard AR, Vollertsen J (2019a) Microplastics in urban and highway stormwater retention ponds. Sci. Total Environ., 671:992-1000

Liu J, Yang Y, Ding J, Zhu B, Gao W (2019b) Microfibers: a preliminary discussion on their definition and sources. Environ. Sci. Pollut. Res., 26:29497-29501

Liu Z, Cai M, Wu D, Yu P, Jiao Y, Jiang Q, Zhao Y (2020) Effects of nanoplastics at predicted environmental concentration on Daphnia pulex after exposure through multiple generations. Environ. Pollut., 256:113506

Liu Z, Li Y, Pérez E, Jiang Q, Chen Q, Jiao Y, Huang Y, Yang Y, Zhao Y (2021) Polystyrene nanoplastic induces oxidative stress, immune defense, and glycometabolism change in Daphnia pulex: Application of transcriptome profiling in risk assessment of nanoplastics. J. Hazard. Mater., 402:123778

Löder MGJ, Kuczera M, Mintenig S, Lorenz C, Gerdts G (2015) Focal plane array detector-based micro-Fourier-transform infrared imaging for the analysis of microplastics in environmental samples. Environ. Chem., 12:563-581

Lohmann R (2017) Microplastics are not important for the cycling and bioaccumulation of organic pollutants in the oceans - but should microplastics be considered POPs themselves? Integr. Environ. Assess. Manage., 13:460-465

Lorenzo-Navarro J, Castrillón-Santana M, Santesarti E, Marsico MD, Martínez I, Raymond E, Gómez M, Herrera A (2020) SMACC: A system for microplastics automatic counting and classification. IEEE Access, 8:25249-25261

Lusher A (2015) Microplastics in the marine environment: Distribution, interactions and effects. In: Bergmann M, Gutow L, Klages M (eds) Marine Anthropogenic Litter. Springer International Publishing, Cham, pp 245-307.

Lusher AL, Burke A, O'Connor I, Officer R (2014) Microplastic pollution in the Northeast Atlantic Ocean: Validated and opportunistic sampling. Mar. Pollut. Bull., 88:325-333

Lusher AL, Tirelli V, O'Connor I, Officer R (2015) Microplastics in Arctic polar waters: the first reported values of particles in surface and sub-surface samples. Sci. Rep., 5:14947

Lv L, Yan X, Feng L, Jiang S, Lu Z, Xie H, Sun S, Chen J, Li C (2020) Challenge for the detection of microplastics in the environment. Water Environ. Res., 93:5-15

Maes T, Van der Meulen MD, Devriese LI, Leslie HA, Huvet A, Frère L, Robbens J, Vethaak AD (2017) Microplastics baseline surveys at the water surface and in sediments of the NorthEast Atlantic, 4

Magni S, Binelli A, Pittura L, Avio CG, Della Torre C, Parenti CC, Gorbi S, Regoli F (2019) The fate of microplastics in an Italian Wastewater Treatment Plant. Sci. Total Environ., 652:602610 
Martínez-Campos S, González-Pleiter M, Fernández-Piñas F, Rosal R, Leganés F (2021) Early and differential bacterial colonization on microplastics deployed into the effluents of wastewater treatment plants. Sci. Total Environ., 757:143832

Mateos-Cárdenas A, O'Halloran J, van Pelt FNAM, Jansen MAK (2020) Rapid fragmentation of microplastics by the freshwater amphipod Gammarus duebeni (Lillj.). Sci. Rep., 10:1-12

Mato Y, Isobe T, Takada H, Kanehiro H, Ohtake C, Kaminuma T (2001) Plastic resin pellets as a transport medium for toxic chemicals in the marine environment. Environ. Sci. Technol., 35:318-324

Mattsson K, Hansson LA, Cedervall T (2015) Nano-plastics in the aquatic environment. Environ. Sci. Processes Impacts, 17:1712-1721

McCormick A, Hoellein TJ, Mason SA, Schluep J, Kelly JJ (2014) Microplastic is an abundant and distinct microbial habitat in an urban river. Environ. Sci. Technol., 48:11863-11871

McCormick AR, Hoellein TJ, London MG, Hittie J, Scott JW, Kelly JJ (2016) Microplastic in surface waters of urban rivers: concentration, sources, and associated bacterial assemblages. Ecosphere, 7:e01556

Meyns M, Primpke S, Gerdts G (2019) Library based identification and characterisation of polymers with nano-FTIR and IR-sSNOM imaging. Anal. Methods, 11:5195-5202

Miller ME, Kroon FJ, Motti CA (2017) Recovering microplastics from marine samples: A review of current practices. Mar. Pollut. Bull., 123:6-18

Mitrano DM, Beltzung A, Frehland S, Schmiedgruber M, Cingolani A, Schmidt F (2019) Synthesis of metal-doped nanoplastics and their utility to investigate fate and behaviour in complex environmental systems. Nat. Nanotechnol., 14:362-368

Moore CJ, Moore SL, Leecaster MK, Weisberg SB (2001) A Comparison of Plastic and Plankton in the North Pacific Central Gyre. Mar. Pollut. Bull., 42:1297-1300

Moore CJ, Moore SL, Weisberg SB, Lattin GL, Zellers AF (2002) A comparison of neustonic plastic and zooplankton abundance in southern California's coastal waters. Mar. Pollut. Bull., 44:1035-1038

Munno K, Helm PA, Jackson DA, Rochman C, Sims A (2018) Impacts of temperature and selected chemical digestion methods on microplastic particles. Environ. Toxicol. Chem., 37:91-98

Murphy F, Ewins C, Carbonnier F, Quinn B (2016) Wastewater treatment works (WwTW) as a source of microplastics in the aquatic environment. Environ. Sci. Technol., 50:5800-5808

Nakamura H, Watano S (2018) Direct permeation of nanoparticles across cell membrane: a review. Kona Powder and Particle Journal, 35: 49-65

Napper IE, Thompson RC (2016) Release of synthetic microplastic plastic fibres from domestic washing machines: Effects of fabric type and washing conditions. Mar. Pollut. Bull., $112: 39-45$

Obbard RW, Sadri S, Wong YQ, Khitun AA, Baker I, Thompson RC (2014) Global warming releases microplastic legacy frozen in Arctic Sea ice. Earth's Future, 2:315-320

Oberbeckmann S, Loeder MGJ, Gerdts G, Osborn AM (2014) Spatial and seasonal variation in diversity and structure of microbial biofilms on marine plastics in Northern European waters. FEMS Microbiol. Ecol., 90:478-492

Oberbeckmann S, Osborn AM, Duhaime MB (2016) Microbes on a bottle: Substrate, season and geography influence community composition of microbes colonizing marine plastic debris. PLoS One, 11:e0159289

Ogonowski M, Motiei A, Ininbergs K, Hell E, Gerdes Z, Udekwu KI, Bacsik Z, Gorokhova E (2018) Evidence for selective bacterial community structuring on microplastics. Environ. Microbiol., 20:2796-2808

Ojha N, Pradhan N, Singh S, Barla A, Shrivastava A, Khatua P, Rai V, Bose S (2017) Evaluation of HDPE and LDPE degradation by fungus, implemented by statistical optimization. Sci. Rep., $7: 39515$ 
Panagiotidou E, Konidaris C, Baklavaridis A, Zuburtikudis I, Achilias D, Mitlianga P (2014) A Simple Route for Purifying Extracellular Poly(3-hydroxybutyrate)-depolymerase from Penicillium pinophilum. Enzyme Research, 2014:159809

Pärnänen KMM, Narciso-da-Rocha C, Kneis D, Berendonk TU, Cacace D, Do TT, Elpers C, FattaKassinos D, Henriques I, Jaeger T, Karkman A, Martinez JL, Michael SG, MichaelKordatou I, O’Sullivan K, Rodriguez-Mozaz S, Schwartz T, Sheng H, Sørum H, Stedtfeld RD, Tiedje JM, Giustina SVD, Walsh F, Vaz-Moreira I, Virta M, Manaia CM (2019) Antibiotic resistance in European wastewater treatment plants mirrors the pattern of clinical antibiotic resistance prevalence. Sci. Adv., 5:eaau9124

Pauly JL, Stegmeier SJ, Allaart HA, Cheney RT, Zhang PJ, Mayer AG, Streck RJ (1998) Inhaled cellulosic and plastic fibers found in human lung tissue. Cancer Epidemiol. Biomarkers Prev., 7:419-428

Pedrotti ML, Petit S, Elineau A, Bruzaud S, Crebassa J-C, Dumontet B, Martí E, Gorsky G, Cózar A (2016) Changes in the Floating Plastic Pollution of the Mediterranean Sea in Relation to the Distance to Land. PLoS One, 11:e0161581

Peeken I, Primpke S, Beyer B, Gütermann J, Katlein C, Krumpen T, Bergmann M, Hehemann L, Gerdts G (2018) Arctic sea ice is an important temporal sink and means of transport for microplastic. Nat. Commun., 9:1505

Peng L, Fu D, Qi H, Lan CQ, Yu H, Ge C (2020) Micro- and nano-plastics in marine environment: Source, distribution and threats - A review. Sci. Total Environ., 698:134254

Peñalver R, Arroyo-Manzanares N, López-García I, Hernández-Córdoba M (2020) An overview of microplastics characterization by thermal analysis. Chemosphere, 242:125170

Petersen EJ, Mortimer M, Burgess RM, Handy R, Hanna S, Ho KT, Johnson M, Loureiro S, Selck H, Scott-Fordsmand JJ, Spurgeon D, Unrine J, van den Brink NW, Wang Y, White J, Holden P (2019) Strategies for robust and accurate experimental approaches to quantify nanomaterial bioaccumulation across a broad range of organisms. Environ. Sci. Nano, 6:1619-1656

PlasticsEurope (2020) Plastics - the Facts 2020: An analysis of European plastics production, demand and waste data. Plastics - the Facts 2020: An analysis of European plastics production, demand and waste data. Brussels.

Prata JC, da Costa JP, Duarte AC, Rocha-Santos T (2019a) Methods for sampling and detection of microplastics in water and sediment: A critical review. TRAC Trends Anal. Chem., 110:150-159

Prata JC, Reis V, Matos JTV, da Costa JP, Duarte AC, Rocha-Santos T (2019b) A new approach for routine quantification of microplastics using Nile Red and automated software (MPVAT). Sci. Total Environ., 690:1277-1283

Primpke S, Christiansen SH, Cowger WC, De Frond H, Deshpande A, Fischer M, Holland E, Meyns M, O'Donnell BA, Ossmann B, Pittroff M, Sarau G, Scholz-Böttcher BM, Wiggin K (2020) EXPRESS: Critical Assessment of Analytical Methods for the Harmonized and Cost Efficient Analysis of Microplastics. Appl. Spectrosc.: 3702820921465

Puglisi E, Romaniello F, Galletti S, Boccaleri E, Frache A, Cocconcelli PS (2019) Selective bacterial colonization processes on polyethylene waste samples in an abandoned landfill site. Sci. Rep., 9:14138

Rao JP, Geckeler KE (2011) Polymer nanoparticles: Preparation techniques and size-control parameters. Prog. Polym. Sci., 36:887-913

Rist S, Vianello A, Winding MHS, Nielsen TG, Almeda R, Torres RR, Vollertsen J (2020) Quantification of plankton-sized microplastics in a productive coastal Arctic marine ecosystem. Environ. Pollut., 266:115248

Roch S, Friedrich C, Brinker A (2020) Uptake routes of microplastics in fishes: practical and theoretical approaches to test existing theories. Sci. Rep., 10:3896 
Rodrigues JP, Duarte AC, Santos-Echeandía J, Rocha-Santos T (2019) Significance of interactions between microplastics and POPs in the marine environment: A critical overview. TRAC Trends Anal. Chem., 111:252-260

Romera-Castillo C, Pinto M, Langer TM, Álvarez-Salgado XA, Herndl GJ (2018) Dissolved organic carbon leaching from plastics stimulates microbial activity in the ocean. Nat. Commun., 9:1430

Ruiz-Orejón LF, Sardá R, Ramis-Pujol J (2016) Floating plastic debris in the Central and Western Mediterranean Sea. Mar. Environ. Res., 120:136-144

Russell JR, Huang J, Anand P, Kucera K, Sandoval AG, Dantzler KW, Hickman D, Jee J, Kimovec FM, Koppstein D, Marks DH, Mittermiller PA, Núñez SJ, Santiago M, Townes MA, Vishnevetsky M, Williams NE, Vargas MPN, Boulanger L-A, Bascom-Slack C, Strobel SA (2011) Biodegradation of polyester polyurethane by endophytic fungi. Appl. Environ. Microbiol., 77:6076-6084

Saido K, Koizumi K, Sato H, Ogawa N, Kwon BG, Chung S-Y, Kusui T, Nishimura M, Kodera Y (2014) New analytical method for the determination of styrene oligomers formed from polystyrene decomposition and its application at the coastlines of the North-West Pacific Ocean. Sci. Total Environ., 473-474:490-495

Salvador-Cesa F, Turra A, Baruque-Ramos J (2017) Synthetic fibers as microplastics in the marine environment: A review from textile perspective with a focus on domestic washings. Sci. Total Environ., 598:1116-1129

SAM (2019) Environmental and Health Risks of Microplastic Pollution. Environmental and Health Risks of Microplastic Pollution. Publications Office of the European Union. Luxembourg.

SAPEA (2019) A Scientific Perspective on Microplastics in Nature and Society. A Scientific Perspective on Microplastics in Nature and Society. Berlin.

Schell T, Cherta L, Dafouz R, Rico A, Vighi M (2020a) Bioconcentration of organic contaminants in fish in the presence of microplastics: Is the "Trojan horse" effect a matter of concern? Paper presented at the SETAC Europe, 30th Annual Meeting, Dublin,

Schell T, Rico A, Vighi M (2020b) Occurrence, fate and fluxes of plastics and microplastics in terrestrial and freshwater ecosystems. Rev. Environ. Contam. Toxicol., [doi:10.1007/398_2019_40]

Schönlau C, Karlsson TM, Rotander A, Nilsson H, Engwall M, van Bavel B, Kärrman A (2020) Microplastics in sea-surface waters surrounding Sweden sampled by manta trawl and in-situ pump. Mar. Pollut. Bull., 153:111019

Schultz SG (1976) Transport across epithelia: Some basic principles. Kidney Int., 9:65-75

Schür C, Rist S, Baun A, Mayer P, Hartmann NB, Wagner M (2019) When fluorescence is not a particle: The tissue translocation of microplastics in Daphnia magna seems an artifact. Environ. Toxicol. Chem., 38:1495-1503

Schymanski D, Goldbeck C, Humpf H-U, Fürst P (2018) Analysis of microplastics in water by micro-Raman spectroscopy: Release of plastic particles from different packaging into mineral water. Water Res., 129:154-162

Seghers J, Stefaniak EA, La Spina R, Cella C, Mehn D, Gilliland D, Held A, Jacobsson U, Emteborg H (2021) Preparation of a reference material for microplastics in waterevaluation of homogeneity. Anal. Bioanal. Chem.

Setälä O, Magnusson K, Lehtiniemi M, Norén F (2016) Distribution and abundance of surface water microlitter in the Baltic Sea: A comparison of two sampling methods. Mar. Pollut. Bull., 110:177-183

Shah AA, Hasan F, Hameed A, Ahmed S (2007) Isolation and characterization of poly(3hydroxybutyrate-co-3-hydroxyvalerate) degrading bacteria and purification of PHBV depolymerase from newly isolated Bacillus sp. AF3. Int. Biodet. Biodeg., 60:109-115 
Shruti VC, Pérez-Guevara F, Kutralam-Muniasamy G (2020) Metro station free drinking water fountain- A potential "microplastics hotspot" for human consumption. Environ. Pollut., 261:114227

Silva AB, Bastos AS, Justino CIL, da Costa JP, Duarte AC, Rocha-Santos TAP (2018) Microplastics in the environment: Challenges in analytical chemistry - A review. Anal. Chim. Acta, 1017:1-19

Skariyachan S, Setlur AS, Naik SY, Naik AA, Usharani M, Vasist KS (2017) Enhanced biodegradation of low and high-density polyethylene by novel bacterial consortia formulated from plastic-contaminated cow dung under thermophilic conditions. Environ. Sci. Pollut. Res., 24:8443-8457

Skjolding LM, Ašmonaitė G, Jølck RI, Andresen TL, Selck H, Baun A, Sturve J (2017) An assessment of the importance of exposure routes to the uptake and internal localisation of fluorescent nanoparticles in zebrafish (Danio rerio), using light sheet microscopy. Nanotoxicology, 11:351-359

Solomon K, Matthies M, Vighi M (2013) Assessment of PBTs in the European Union: a critical assessment of the proposed evaluation scheme with reference to plant protection products. Environ. Sci. Eur. Environ Sci Eur, 25:10

Song YK, Hong SH, Jang M, Kang J-H, Kwon OY, Han GM, Shim WJ (2014) Large accumulation of micro-sized synthetic polymer particles in the sea surface microlayer. Environ. Sci. Technol., 48:9014-9021

Stephens B, Azimi P, El Orch Z, Ramos T (2013) Ultrafine particle emissions from desktop 3D printers. Atmos. Environ., 79:334-339

Suaria G, Avio CG, Mineo A, Lattin GL, Magaldi MG, Belmonte G, Moore CJ, Regoli F, Aliani S (2016) The mediterranean plastic soup: Synthetic polymers in Mediterranean surface waters. Sci. Rep., 6:37551

Suhrhoff TJ, Scholz-Böttcher BM (2016) Qualitative impact of salinity, UV radiation and turbulence on leaching of organic plastic additives from four common plastics - A lab experiment. Mar. Pollut. Bull., 102:84-94

Sullivan GL, Gallardo JD, Jones EW, Hollliman PJ, Watson TM, Sarp S (2020) Detection of trace sub-micron (nano) plastics in water samples using pyrolysis-gas chromatography time of flight mass spectrometry (PY-GCToF). Chemosphere, 249:126179

Sultan I, Rahman S, Jan AT, Siddiqui MT, Mondal AH, Haq QMR (2018) Antibiotics, resistome and resistance mechanisms: A bacterial perspective. Front. Microbiol., 9:2066-2066

Sun X, Li Q, Shi Y, Zhao Y, Zheng S, Liang J, Liu T, Tian Z (2019) Characteristics and retention of microplastics in the digestive tracts of fish from the Yellow Sea. Environ. Pollut., 249:878-885

Talvitie J, Mikola A, Koistinen A, Setälä O (2017a) Solutions to microplastic pollution - Removal of microplastics from wastewater effluent with advanced wastewater treatment technologies. Water Res., 123:401-407

Talvitie J, Mikola A, Setälä O, Heinonen M, Koistinen A (2017b) How well is microlitter purified from wastewater? - A detailed study on the stepwise removal of microlitter in a tertiary level wastewater treatment plant. Water Res., 109:164-172

Tetu SG, Sarker I, Schrameyer V, Pickford R, Elbourne LDH, Moore LR, Paulsen IT (2019) Plastic leachates impair growth and oxygen production in Prochlorococcus, the ocean's most abundant photosynthetic bacteria. Commun. Biol., 2:184

Teuten EL, Rowland SJ, Galloway TS, Thompson RC (2007) Potential for plastics to transport hydrophobic contaminants. Environ. Sci. Technol., 41:7759-7764

Thiel M, Luna-Jorquera G, Álvarez-Varas R, Gallardo C, Hinojosa IA, Luna N, Miranda-Urbina D, Morales N, Ory N, Pacheco AS, Portflitt-Toro M, Zavalaga C (2018) Impacts of marine plastic pollution from continental coasts to subtropical gyres-Fish, seabirds, and other vertebrates in the SE Pacific. Front. Mar. Sci., 5:238 
Tourinho PS, Kočí V, Loureiro S, van Gestel CAM (2019) Partitioning of chemical contaminants to microplastics: Sorption mechanisms, environmental distribution and effects on toxicity and bioaccumulation. Environ. Pollut., 252:1246-1256

Triebskorn R, Braunbeck T, Grummt T, Hanslik L, Huppertsberg S, Jekel M, Knepper TP, Krais S, Müller YK, Pittroff M, Ruhl AS, Schmieg H, Schür C, Strobel C, Wagner M, Zumbülte N, Köhler H-R (2019) Relevance of nano- and microplastics for freshwater ecosystems: A critical review. TRAC Trends Anal. Chem., 110:375-392

Troost TA, Desclaux T, Leslie HA, van Der Meulen MD, Vethaak AD (2018) Do microplastics affect marine ecosystem productivity? Mar. Pollut. Bull., 135:17-29

UNEP (2016) Marine plastic debris \& microplastics - Global lessons and research to inspire action and guide policy change. Programme UNE (ed) Marine plastic debris \& microplastics Global lessons and research to inspire action and guide policy change. Nairobi.

van der Hal N, Ariel A, Angel DL (2017) Exceptionally high abundances of microplastics in the oligotrophic Israeli Mediterranean coastal waters. Mar. Pollut. Bull., 116:151-155

van Doremalen N, Bushmaker T, Morris DH, Holbrook MG, Gamble A, Williamson BN, Tamin A, Harcourt JL, Thornburg NJ, Gerber SI, Lloyd-Smith JO, de Wit E, Munster VJ (2020) Aerosol and surface stability of SARS-CoV-2 as compared with SARS-CoV-1. N. Engl. J. Med., 382:1564-1567

van Mourik LM, Crum S, Martinez-Frances E, van Bavel B, Leslie HA, de Boer J, Cofino WP (2021) Results of WEPAL-QUASIMEME/NORMANs first global interlaboratory study on microplastics reveal urgent need for harmonization. Sci. Total Environ., 772:145071

Verhaar HJM, van Leeuwen CJ, Hermens JLM (1992) Classifying environmental pollutants. Chemosphere, 25:471-491

Verma R, Vinoda KS, Papireddy M, Gowda ANS (2016) Toxic Pollutants from Plastic Waste-A Review. Procedia Environ. Sci., 35:701-708

Vianello A, Jensen RL, Liu L, Vollertsen J (2019) Simulating human exposure to indoor airborne microplastics using a Breathing Thermal Manikin. Sci. Rep., 9:8670

Wang F, Wong CS, Chen D, Lu X, Wang F, Zeng EY (2018) Interaction of toxic chemicals with microplastics: A critical review. Water Res., 139:208-219

Wang S, Xue N, Li W, Zhang D, Pan X, Luo Y (2020) Selectively enrichment of antibiotics and ARGs by microplastics in river, estuary and marine waters. Sci. Total Environ., 708:134594

Webb HK, Crawford RJ, Sawabe T, Ivanova EP (2009) Poly(ethylene terephthalate) polymer surfaces as a substrate for bacterial attachment and biofilm formation. Microbes Environ., 24:39-42

WEF (2016) The new plastics economy: Rethinking the future of plastics. World Economic Forum, Geneve, Switzerland.

Wesch C, Bredimus K, Paulus M, Klein R (2016) Towards the suitable monitoring of ingestion of microplastics by marine biota: A review. Environ. Pollut., 218:1200-1208

Wright SL, Thompson RC, Galloway TS (2013) The physical impacts of microplastics on marine organisms: A review. Environ. Pollut., 178:483-492

Wright SL, Ulke J, Font A, Chan KLA, Kelly FJ (2020) Atmospheric microplastic deposition in an urban environment and an evaluation of transport. Environ. Int., 136:105411

$\mathrm{Xu}$ J-L, Thomas KV, Luo Z, Gowen AA (2019) FTIR and Raman imaging for microplastics analysis: State of the art, challenges and prospects. TRAC Trends Anal. Chem., 119:115629

Yakovenko N, Carvalho A, ter Halle A (2020) Emerging use thermo-analytical method coupled with mass spectrometry for the quantification of micro(nano)plastics in environmental samples. TRAC Trends Anal. Chem., 131:115979

Yang Y, Liu G, Song W, Ye C, Lin H, Li Z, Liu W (2019) Plastics in the marine environment are reservoirs for antibiotic and metal resistance genes. Environ. Int., 123:79-86

Zettler ER, Mincer TJ, Amaral-Zettler LA (2013) Life in the "Plastisphere": Microbial communities on plastic marine debris. Environ. Sci. Technol., 47:7137-7146 
Zhang H, Kuo Y-Y, Gerecke AC, Wang J (2012) Co-release of hexabromocyclododecane (HBCD) and nano- and microparticles from thermal cutting of polystyrene foams. Environ. Sci. Technol., 46:10990-10996

Zhang M, Zhao Y, Qin X, Jia W, Chai L, Huang M, Huang Y (2019a) Microplastics from mulching film is a distinct habitat for bacteria in farmland soil. Sci. Total Environ., 688:470-478

Zhang W, Dong Z, Zhu L, Hou Y, Qiu Y (2020) Direct Observation of the Release of Nanoplastics from Commercially Recycled Plastics with Correlative Raman Imaging and Scanning Electron Microscopy. ACS Nano, 14:7920-7926

Zhang Y, Gao T, Kang S, Sillanpää M (2019b) Importance of atmospheric transport for microplastics deposited in remote areas. Environ. Pollut., 254:112953

Zhu L, Zhao S, Bittar TB, Stubbins A, Li D (2020) Photochemical dissolution of buoyant microplastics to dissolved organic carbon: Rates and microbial impacts. J. Hazard. Mater., 383:121065

Ziajahromi S, Drapper D, Hornbuckle A, Rintoul L, Leusch FDL (2020) Microplastic pollution in a stormwater floating treatment wetland: Detection of tyre particles in sediment. Sci. Total Environ., 713:136356

Zubris KAV, Richards BK (2005) Synthetic fibers as an indicator of land application of sludge. Environ. Pollut., 138:201-211 